\title{
Physical properties of the sub-micrometer aerosol over the Amazon rain forest during the wet-to-dry season transition - comparison of modeled and measured $\mathrm{CCN}$ concentrations
}

\author{
J. Rissler ${ }^{1}$, E. Swietlicki ${ }^{1}$, J. Zhou ${ }^{1}$, G. Roberts ${ }^{2}$, M. O. Andreae ${ }^{3}$, L. V. Gatti ${ }^{4}$, and P. Artaxo ${ }^{5}$ \\ ${ }^{1}$ Div. of Nuclear Physics, Lund University, P.O. Box 118, SE-221 00 Lund, Sweden \\ ${ }^{2}$ Scripps Institution of Oceanography, Center for Atmospheric Sciences, University of California San Diego, USA \\ ${ }^{3}$ Max Planck Institute for Chemistry, P.O. Box 3020, D-55020 Mainz, Germany \\ ${ }^{4}$ IPEN - Instituto de Pesquisas Energéticas e Nucleares, Rua do Matão, 400, São Paulo, S.P., Brazil \\ ${ }^{5}$ Instituto de Fisica da Universidade de Sao Paulo, Sao Paulo, Brazil
}

Received: 26 February 2004 - Published in Atmos. Chem. Phys. Discuss.: 15 June 2004

Revised: 15 October 2004 - Accepted: 25 October 2004 - Published: 2 November 2004

\begin{abstract}
Sub-micrometer atmospheric aerosol particles were studied in the Amazon region, $125 \mathrm{~km}$ northeast of Manaus, Brazil $\left(-1^{\circ} 55.2^{\prime} \mathrm{S}, 59^{\circ} 28.1^{\prime} \mathrm{W}\right)$. The measurements were performed during the wet-to-dry transition period, 4-28 July 2001 as part of the LBA (Large-Scale Biosphere Atmosphere Experiment in Amazonia) CLAIRE2001 (Cooperative LBA Airborne Regional Experiment) experiment. The number size distribution was measured with two parallel differential mobility analyzers, the hygroscopic growth at 90\% RH with a Hygroscopic Tandem Mobility Analyzer (H-TDMA) and the concentrations of cloud condensation nuclei $(\mathrm{CCN})$ with a cloud condensation nuclei counter. A model was developed that uses the H-TDMA data to predict the number of soluble molecules or ions in the individual particles and the corresponding minimum particle diameter for activation into a cloud droplet at a certain supersaturation. Integrating the number size distribution above this diameter, $\mathrm{CCN}$ concentrations were predicted with a time resolution of $10 \mathrm{~min}$ and compared to the measured concentrations. During the study period, three different air masses were identified and compared: clean background, air influenced by aged biomass burning, and moderately polluted air from recent local biomass burning. For the clean period 2001, similar number size distributions and hygroscopic behavior were observed as during the wet season at the same site in 1998, with mostly internally mixed particles of low diameter growth factor ( $\sim 1.3$ taken from dry to $90 \% \mathrm{RH})$. During the periods influenced by biomass burning the hygroscopic growth changed slightly, but the largest difference was seen in the number size distribution. The $\mathrm{CCN}$ model was found to be successful in predicting the measured $\mathrm{CCN}$ concentrations,
\end{abstract}

Correspondence to: J. Rissler

(jenny.rissler@pixe.lth.se) typically within $25 \%$. A sensitivity study showed relatively small dependence on the assumption of which model salt that was used to predict $\mathrm{CCN}$ concentrations from H-TDMA data. One strength of using H-TDMA data to predict CCN concentrations is that the model can also take into account soluble organic compounds, insofar as they go into solution at $90 \% \mathrm{RH}$. Another advantage is the higher time resolution compared to using size-resolved chemical composition data.

\section{Introduction}

The climate forcing by atmospheric aerosols results from scattering and absorption of solar radiation (direct effect), and from particles acting as cloud condensation nuclei $(\mathrm{CCN})$, thereby indirectly affecting the radiative balance as a result of changes in cloud properties. According to the IPCC (Intergovernmental Panel on Climate Change) report (IPCC, 2001), the largest uncertainty in climate forcing arises from a lack of understanding of the indirect effect of aerosols on climate. This uncertainty is so large, that it even includes the theoretical possibility of a present-day zero net climate forcing (Anderson et al., 2003). It is therefore important to investigate further how aerosols of human origin influence cloud properties in order to derive a more accurate estimate of their net radiative effect. A better understanding of natural aerosol forcing is also critical to quantitatively assess the environmental changes that regions such as Amazonia are exposed to.

In the pristine continental tropics, background aerosol concentrations are usually very low (Artaxo et al., 2002; Zhou et al., 2002; Roberts et al., 2001). This makes the region sensitive to aerosol indirect effects resulting from even 
modest increases in aerosol loadings. Such effects include the modification of the vertical energy balance of the troposphere and the hydrological cycle due to changes in the precipitation patterns (Williams et al., 2002), with potential implications for both regional and global climate (Andreae et al., 2004; Nober et al., 2003). However, our ability to assess the changes in precipitation patterns due to human-induced modifications of the tropical aerosol is limited (IPCC, 2001, summary chapter 5). The Amazon basin plays an important role in global carbon cycling and, as part of the tropical region also in the budget of OH-radicals, which cleanse the air from anthropogenic trace gases such as hydrocarbons, $\mathrm{CO}$ and $\mathrm{NO}_{\mathrm{x}}$. It is therefore of great importance to understand this system (Crutzen and Andreae, 1990).

Until recently, only the inorganic components were taken into account when modeling the $\mathrm{CCN}$ properties of aerosol particles. Lately, several studies have pointed to the potentially important role of water-soluble organic compounds (WSOC) in cloud droplet formation through their ability to contribute soluble material and lower the surface tension, thereby decreasing the critical supersaturation needed for droplet activation (Cruz et al., 1997; Facchini et al., 2000; Novakov et al., 1993; and Laaksonen et al., 1998). In an earlier study, it was shown that about $80 \%$ of the submicrometer particle mass in Amazonia consisted of organic material, $15 \%$ of ammonium sulfate and $5 \%$ of other inorganic material (Roberts et al., 2002). It is therefore of interest to investigate further the cloud nucleating properties of the aerosol particles in the region, in order to develop simple models for predictions of CCN concentrations, as well as to get a better understanding of the influence of organic compounds.

Although the Amazon region is of great climatic importance, little information is available on the particle hygroscopic properties and $\mathrm{CCN}$ concentrations, especially in a fairly unpolluted area like our study region. To our knowledge only one previous study of the kind presented here has been made for the Amazon region (Zhou et al, 2002; Roberts et al., 2001; Roberts et al., 2002). That study, LBA/CLAIRE-98 (Large-Scale Biosphere Atmosphere Experiment in Amazonia/Cooperative LBA Airborne Regional Experiment), was carried out during the wet season in early 1998. During the SCAR-B (Smoke, Clouds and Radiation Brazil) experiment, the $\mathrm{CCN}$ concentrations were compared to particle number concentrations, but no H-TDMA (Hygroscopic Tandem Mobility Analyzer, see Sect. 2.2.1) was used and no CCN closure was made (Kaufman et al., 1998).

The present study focused on the hygroscopic properties of the aerosol particles and their role as $\mathrm{CCN}$ observed during the second LBA/CLAIRE-campaign (LBA/CLAIRE-2001), which was carried out in July 2001.

The aims of the study were:

1. to provide a characterization of the submicrometer aerosol physical and cloud-nucleating properties and their variability during the wet-to-dry transition period in Amazonia, and compare with those of the wet season,

2. to predict CCN concentrations from measurements of dry aerosol particle size distributions and hygroscopic properties using an extension of the classical Köhler theory, and validate the predictions against actual $\mathrm{CCN}$ measurements (our hypothesis is that the number of soluble ions/molecules can explain the cloud nucleating properties),

3. to carry out a model sensitivity study; and finally,

4. to provide a parameterization of the predicted $\mathrm{CCN}$ spectra.

Recently, Nenes and Seinfeld (2003) suggested a new parameterization of cloud droplet formation in global climate models, taking into account also some of the important kinetic limitations to droplet growth. The Nenes and Seinfeld (2003) model requires a description of the $\mathrm{CCN}$ properties of the aerosol entering the cloud in the form of $d N_{C C N} / d s$, that is the number of particles that activate as a function of the supersaturation $s$ in the cloud. The cumulative representation of $d N_{C C N} / d s$ is simply the CCN spectrum, $N_{C C N}(s)$, describing the number of aerosol particles that has activated and formed cloud droplets at or below a given supersaturation.

We propose that the $\mathrm{CCN}$ spectrum (and therefore also $\left.d N_{C C N} / d s\right)$ can be estimated from the fundamental aerosol physical properties; the number size distribution and the soluble volume fraction. The latter quantity can be estimated from H-TDMA measurements, and refers to a model compound, for instance a certain salt. Numerous other H-TDMA and size distribution data sets exist for a large variety of other environments world-wide, and they could be used for the same purpose (Swietlicki et al., 2000; Massling et al., 2003; Zhou et al., 2001a; Hämeri et al., 2001; Zhang et al., 1993; Berg et al., 1998; Svenningsson et al., 1992; Svenningsson et al., 1994; Swietlicki et al., 1999). Even though global climate models at present are not able to fully incorporate this information and the parameterization of cloud droplet formation suggested by Nenes and Seinfeld (2003), they must at some point address this issue. If not, the large uncertainty in our ability to predict future climate change due to the aerosol indirect forcing will remain.

The measurements were performed at a ground station in Balbina, situated in the northern part of the Brazilian rainforest with several hundred kilometers of untouched rainforest in the upwind direction. These conditions made it a suitable place for studying the naturally emitted aerosols from a relatively unperturbed ecosystem, as well as the effects of human activities on this pristine environment. The measurements took place during the wet-to-dry transition period.

In Sect. 2, the physical properties of the particles are presented and compared to the results from the wet period in 
1998. A theoretical prediction of CCN concentrations is made from the DMPS (Differential Mobility Particle Sizer) and H-TDMA measurements. The predicted concentrations are discussed and compared to measured $\mathrm{CCN}$ concentrations in Sect. 3. The particle physical properties for three selected different periods - clean background, aged biomass burning and recent biomass burning - are compared in Sects. 4 and 5. In order to characterize the clean background aerosol further, the model is also applied to the data set from LBA/CLAIRE-98. A sensitivity study of the model is carried out varying the size distribution as well as using different model compounds for the prediction of the critical supersaturation. In Sect. 6, a parameterization of the predicted CCN concentrations is made and an even simpler model presented that enables direct calculation of CCN concentrations even when a full chemical characterization of the aerosol is not available.

The work discussed here has been continued with a study of the aerosol during the dry period in a heavily polluted area with particles from biomass burning in Rondônia, Brazil, September-November 2002 (Swietlicki et al., 2003).

\section{The Experiment}

\subsection{Experimental conditions}

Data were acquired at a ground site at Balbina $\left(1^{\circ} 55.2^{\prime} \mathrm{S}\right.$, $59^{\circ} 28.1^{\prime} \mathrm{W}$ ), situated about $125 \mathrm{~km}$ northeast of Manaus (Fig. 1). With hundreds of kilometers of pristine rainforest in the predominant up-wind direction, Balbina is an excellent location for studying the natural conditions of Amazonian rainforests, as well as long-range transported pollution and occasional events of fresh pollution. Measurements were performed during the transition period between the wet and dry seasons, 4-28 July 2001. During a part of this period, clean conditions similar to those measured in CLAIRE-98 (Zhou et al., 2002) could be seen, as well as periods with a clear influence of biomass burning.

Trace gas and meteorological measurements were carried out at the site in addition to the aerosol measurements. Flight measurements were made over the site and nearby, as well as measurements from a boat on the Amazon River around Manaus. Additional ground station measurements, mostly of trace gases, were done at a station $22 \mathrm{~km}$ southeast of Balbina.

\subsection{Instrumentation}

The aerosol was sampled through an inlet with a $5 \mu \mathrm{m}$ cutoff placed about $6 \mathrm{~m}$ above ground. The DMPS (Differential Mobility Particle Sizer, see Sect. 2.2.2), an additional particle counter, the H-TDMA, and a thermal-gradient CCN-counter were all sampling from this same inlet. The DMPS and the H-TDMA were designed, built, calibrated and operated by the Division of Nuclear Physics, Lund University, Sweden.

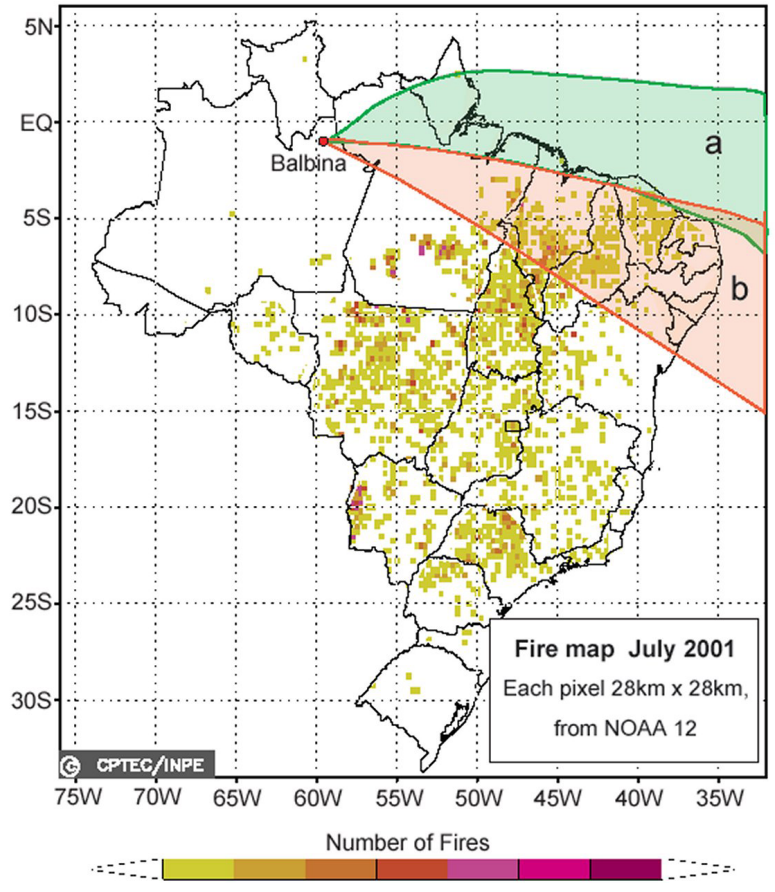

Fig. 1. Map showing fire spots in Brazil during July 2001 detected by the NOAA-12 satellite, and compiled by CPTEC/INPE. Wind sector $a$ shows the area swept by the air mass back trajectories during the clean and recent biomass burning period (green borders), and wind sector $b$ during the aged biomass burning period (red borders).

The thermal-gradient $\mathrm{CCN}$-counter was designed, built and operated by the Max Planck Institute for Chemistry, Mainz, Germany.

\subsubsection{The H-TDMA}

Measurements of the hygroscopic properties of submicrometer aerosol particles were performed with an $\mathrm{H}-$ TDMA (Hygroscopic Tandem Differential Mobility Analyzer) for particle dry sizes between $20-265 \mathrm{~nm}$. The instrument was running more or less continuously during the campaign, with the exception of a break from 17 to 23 July 2001. The H-TDMA measures the hygroscopic diameter growth of particles taken from a dry state (relative humidity $\mathrm{RH}<10 \%$ ) to a state of controlled humidity, nominally $90 \%$. The instrument consists of three main parts: (1) a Differential Mobility Analyzer (DMA1) that selects out a narrow, quasi-monodisperse size range of dry particles from the atmospheric aerosol, (2) humidifiers bringing the aerosol to a controlled humidified state, and (3) a second DMA (DMA2) that measures the change in size caused by the imposed humidification. The aerosol and the sheath flows entering DMA2 are humidified separately.

The humidity was set to $90 \%$ RH most of the time, but a different RH (60\%) was selected at regular intervals to study 
how the hygroscopic growth varied with RH. A more detailed technical description of the H-TDMA can be found in Svenningsson (1997) and Zhou (2001b).

\subsubsection{The DMPS}

A DMPS (Differential Mobility Particle Sizer) was used to measure the dry aerosol particle size distribution in the diameter range 3 to $850 \mathrm{~nm}$. Two DMAs of the "Vienna" type (Winklmayr et al., 1991) were used to scan in parallel from 22 to $850 \mathrm{~nm}$ up, and from 22 to $3 \mathrm{~nm}$ down in size, respectively. Simultaneous measurements were thus carried out at $22 \mathrm{~nm}$, which enabled a check of the data quality. The two DMAs were operated in stepwise scanning mode, scanning in equal logarithmic diameter steps, for a total of 38 mobility channels. Two condensation particle counters (CPC TSI 7610 and TSI 3025) were used for particle detection after each DMA. Both CPCs were calibrated for counting efficiency as a function of particle size. One scan over the whole size range took $10 \mathrm{~min}$.

\subsubsection{The thermal-gradient $\mathrm{CCN}$ counter}

CCN (Cloud Condensation Nuclei) concentrations were measured with a thermal-gradient CCN counter (Roberts, 2001). This instrument measures $\mathrm{CCN}$ concentrations by direct activation of the droplets in a chamber with a controlled super-saturation profile. A video camera connected to a personal computer via a video capture card produces images of the illuminated activated droplets. The pictures are examined with image processing software that determines the number of activated droplets in the illuminated volume. The droplets are removed from the illuminated chamber by gravitational settling, and the maximum droplet concentration is calibrated to represent a measure of the ambient $\mathrm{CCN}$ concentration at the given supersaturation. The $\mathrm{CCN}$ counter was used in Balbina during the last days of the campaign, 23-28 July 2001, having first served in the aircraft measurements.

In order to reduce the experimental biases, the $\mathrm{CCN}$ counter was calibrated, not only with respect to total number, but also supersaturation. In some CCN counter studies the supersaturation is calculated directly from the temperature of the $\mathrm{CCN}$ counter plates. Our calibration in supersaturation showed that a correction by $\sim-0.3 \%$ in supersaturation had to be applied to the supersaturation calculated from the thermal gradient. The reason for the deviation from the nominal values is probably due to the surface temperature of the plates not being equal to the temperature measured inside the plates (Nenes et al., 2001a). The calibration of the $\mathrm{CCN}$ counter was made for supersaturations between 1 and $0.3 \%$ (after correction), using $\mathrm{NaCl}$ particles. In some studies (Gysel et al., 2002), this salt has been noticed to have a cubic or a cubic-like shape. The particle shape can, however, depend on the way the particles are generated and is not taken into account in the calibration used here. The effect would be a slightly higher supersaturation of about $0.05 \%$ when assuming a perfect cubic shape (a dynamic shape factor of 1.08) instead of spherical particles. The estimated uncertainty ( \pm 1 s.d.) in the calibrated critical supersaturations and number concentrations are shown in Fig. 6. This was the first calibration of supersaturation for this $\mathrm{CCN}$ counter, and was made $\sim 1$ year after the experiment.

\subsubsection{Further measurements}

Further measurements referred to in this article are NO, $\mathrm{NO}_{2}$ and $\mathrm{O}_{3}$ concentrations as well as basic meteorological data including precipitation. Back trajectories were calculated with the HYbrid Single-Particle Lagrangian Integrated Trajectory Model (HYSPLIT-model) (Draxler et al., 1998). Images from the NOAA12 and 14 satellites, processed by INPE-CPTEC (Instituto Nacional de Pesquisas Espaciais, Centro de Previsão de Tempo e Estudos Climáticos), were used to map out the location of large-scale biomass burning.

\subsection{Data evaluation}

The raw data obtained by the H-TDMA were evaluated and assured for quality off-line. The spectra were fitted with a fitting program developed in Lund (Zhou, 2001b, Chapter 2.5.2), based on the principles of Stolzenberg and McMurry (1988). The inversion used in this program estimates the arithmetic mean diameter growth factor (defined as the ratio between the dry and conditioned particle diameter), the diameter growth dispersion factor, and the number fractions of particles in each hygroscopic particle group. Throughout the campaign, parameters showing the status of the $\mathrm{H}-$ TDMA were logged and later used to ensure the quality of the data. Requirements for acceptance of data were in accordance with those defined by Swietlicki et al. (2000). The criteria applied are presented in Table 1. To check the functioning of the equipment and to secure the correctness of the relative humidity measurements, the hygroscopic growth of a standard aerosol of pure ammonium sulfate was measured at least once every other day. The growth of the calibration salt particles was then compared to the expected value, calculated using water activity data from Tang and Munkelwitz (1994).

Despite considerable efforts to stabilize the RH in DMA2, slight deviations from the nominal RH are difficult to avoid during field operation. The growth factors were therefore corrected from the actual DMA2 RH to the nominal RH, in most cases $90 \%$. This was done in order to study the temporal variations more clearly, as well as to facilitate comparisons with previous measurements. The salt used for this RH correction was ammonium hydrogen sulfate, which according to previous measurement (Roberts et al., 2002) was the dominating inorganic salt of the particles. The corrections were made as described by Swietlicki et al. (2000). Since the variation in DMA2 RH was relatively small (see Table 1), 
Table 1. Quality assurance criteria used for acceptance of the CLAIRE 2001 H-TDMA data.

\begin{tabular}{lll}
\hline Parameter & Criterion & Purpose \\
\hline DMA2 RH average during scan & $87-93 \%$ & limit range for comparability and to allow correction to 90\% \\
DMA2 RH variability during scan & $\pm 1 \% \mathrm{RH}$ & minimize RH fluctuation during particle classification \\
Temperature difference sheath - excess flow & $\pm 0.4^{\circ} \mathrm{C}$ & minimize RH gradients in DMA2 \\
Relative standard deviation in CPC1 concentration & $<0.4$ & particle concentrations stable during scan \\
Standard deviation of sheath flow RH & $<1 \% \mathrm{RH}$ & DMA2 humidity control working properly \\
Stability of DMA flows during scan & $\pm 1 \%$ sheath & accurate size classification \\
& $\pm 3 \%$ aerosol & accurate concentration measurement
\end{tabular}

the dependence on the type of salt applied in this correction is negligible.

The algorithm for inversion of the DMPS data was developed in Lund (Zhou, 2001b, Chapter 2.3) and written in the LabVIEW graphical programming language (National Instruments). It calculates the theoretical DMPS kernel transfer matrix and inverts the mobility concentrations to an aerosol size distribution. The variables taken into account for calculating the kernel transfer matrix are: sampling line losses, bipolar charging probabilities, calibrated DMA transfer functions, DMA diffusion broadening and losses, and CPC counting efficiencies.

Removal of DMPS data was limited to occasions when the particle concentrations showed clear signs of sudden fluctuations during the 10-min scan, resulting in unrealistic size distributions. The remaining DMPS data were fitted to a bior tri-modal lognormal distribution.

\subsection{Internal consistency tests}

A CPC (TSI 3010) particle counter measured particles from the same aerosol inlet as the DMPS. The DMPS size distributions were integrated for particle sizes larger than $7 \mathrm{~nm}$ (the CPC lower cut-off size) and compared with the concentration measured with the CPC. The correlation was high $\left(r^{2}=0.84\right)$, with the DMPS showing slightly lower particle concentrations compared to the CPC (slope DMPS vs. CPC: 0.93, with zero intercept). One circumstance decreasing the correlation was the different "time resolution" of the two instruments the DMPS was stepping, measuring a particular size only for a short period of the measurement cycle - while the CPC counted all particles continuously (logged every $5 \mathrm{~min}$ ).

\section{CCN Calculation model}

In classical Köhler theory (Köhler, 1936) each particle is assumed to consist of a number of molecules that are soluble in a solvent, normally water. In some cases, an insoluble core is also taken into account. In atmospheric applications, the water-soluble material is often taken to be various common inorganic salts dissociating into ions when in solution, which is actually the case for the original Köhler theory. Organic substances have until recently often been considered insoluble (hydrophobic) and were thus neglected in the theory of droplet formation. Under certain circumstances this is a valid approximation (Martinsson et al, 1999), but recent studies have shown that organic compounds, under certain conditions, can have a significant influence on the water uptake of aerosol particles and their ability to act as cloud condensation nuclei (Charlson et al., 2001; Cruz et al., 1997; Facchini et al., 2000; Novakov et al., 1993; Laaksonen et al., 1998; Roberts et al., 2002). This is due to their ability to dissolve in water (Raoult effect) and their influence on the droplet surface tension (Kelvin effect). They might also inhibit droplet growth if the particles are coated with an organic compound of low solubility (Hansson et al., 1998). In all but the latter case, the combined effect of the organic compounds is to lower the critical water vapor supersaturation required to activate the aerosol particles, and thus facilitate cloud droplet formation.

The approach used here to predict the $\mathrm{CCN}$ concentration was based on Köhler theory, extrapolating the hygroscopic behavior at $90 \%$ RH (measured with the H-TDMA) to supersaturations. One strength of the model is that the possible effect on water uptake of organic compounds is taken into account if in solution at $90 \% \mathrm{RH}$. Since the particle number size distribution in the submicrometer region is the most important aerosol property determining the $\mathrm{CCN}$ concentration, either direct measurements or indirect estimates of the sizeresolved particle number concentrations are also essential.

In Sect. 5, the CCN concentrations predicted by the model are compared to those measured. A sensitivity study is also made on the effect of using different model compounds, taking into account the mixing state, the effect of changes in surface tension, and shifting the size distribution.

\subsection{Model approach}

In brief, the following approach was taken to predict the $\mathrm{CCN}$ concentration. From the measured hygroscopic diameter growth at $90 \% \mathrm{RH}$, the number of soluble molecules or ions, $n_{i}$, in the individual particles was calculated for each 
dry size measured. From $n_{i}$, the critical water vapor supersaturation was calculated for each dry size, and also the smallest dry diameter of a particle that activates at a certain supersaturation (here denoted the activation diameter). All particles above this (dry) activation diameter are assumed to activate and act as CCN. The effect of kinetic limitations on the cloud droplet number concentrations are not considered here (Nenes et al., 2001b).

This approach is similar to that taken by Brechtel et al. (2000a,b), Covert et al. (1988), Dusek et al. (2003) and Zhou et al. (2001a). When the H-TDMA showed a bimodal distribution, the calculation was done separately for each hygroscopic group.

According to classical Köhler theory, the water vapor equilibrium between a dilute (and ideal) solution droplet and its environment can be described as:

$\frac{e}{e_{s}(T)}=S_{w}=\exp \left[\frac{4 M_{w} \sigma_{w}}{R T \rho_{w} D}-\frac{6 v m_{s} M_{w}}{M_{s} \rho_{w} \pi D^{3}}\right]$,

where $e$ is the equilibrium partial pressure over the droplet, $e_{S}(T)$ is the water vapor saturation pressure at temperature $T, S_{w}$ is the water vapor saturation ratio, $D$ the droplet diameter, while $M_{w}, \rho_{w}$ and $\sigma_{w}$ are the molecular weight, density and surface tension of pure water, respectively. Further, $m_{s}$ is the solute mass, $M_{s}$ the solute molecular weight, and $v$ the number of ions resulting from the dissociation of one solute molecule. The first term in the Köhler equation takes into account the increase in equilibrium water vapor pressure caused by the droplet curvature, often called the Kelvin curvature effect, and the second term describes the solution water vapor depression, the Raoult solution effect. This equation can also be written as

$$
\ln S_{w}=\frac{A}{D}-\frac{B}{D^{3}} \quad \text { or } \quad S_{w} \approx 1+\frac{A}{D}-\frac{B}{D^{3}}
$$

where

$$
\begin{aligned}
A & =\frac{4 M_{w} \sigma_{w}}{R T \rho_{w}} ; \\
B & =\frac{6 v m_{s} M_{w}}{\pi M_{s} \rho_{w}}=C \cdot n_{i} ; \\
C & =\frac{6 M_{w}}{\pi \rho_{w}} .
\end{aligned}
$$

In this simplified version, the Köhler curve can therefore be expressed as a function of the properties of pure water, the ambient temperature and finally, the number of solute molecules or ions.

The maximum in the Köhler curve represents the point at which the droplets pass from the equilibrium side of the curve into a state of rapid condensational growth, often denoted the activation of the aerosol particle into a cloud droplet. At this activation point, the approximation made in
Eq. (1) is valid, under most circumstances, and the corresponding critical water vapor saturation ratio, $S_{c}$, is given by

$$
\ln S_{c}=\left(\frac{4 A^{3}}{27 B}\right)^{1 / 2}=\left(\frac{4 A^{3}}{27 C \cdot n_{i}}\right)^{1 / 2} \approx s_{c} .
$$

Here, $s_{c}$ is the critical water vapor supersaturation $\left(S_{c}=1+s_{c}\right.$, recalling that $\ln (1+\mathrm{x}) \approx \mathrm{x}$ as $\mathrm{x} \rightarrow 0)$. Again, $n_{i}$ is the only solute property affecting the water vapor supersaturation $s_{c}$ required to activate a certain aerosol particle (apart from surface tension).

When interpreting H-TDMA data on hygroscopic growth, the soluble material is often represented by a soluble particle volume fraction, $\varepsilon$, of a specific salt. The remaining particle volume is considered inactive from a hygroscopic point of view. The salt used is often chosen to be the dominating salt of the particles, obtained for instance from an ion chromatography analysis. The resulting soluble volume fraction may be different from the actual volume fraction of all watersoluble ionic or molecular compounds in the particle, especially when water-soluble compounds with low hygroscopic growth are present. When examining the calculated values of the soluble volume fractions, care should therefore be taken when using these values for purposes other than those intended here.

The soluble volume fraction, $\varepsilon$, is defined as the particle water-soluble volume divided by total particle volume. It can be estimated from the H-TDMA data (Pitchford and McMurry, 1994) as

$$
\varepsilon=\frac{g_{\varepsilon}^{3}-1}{g_{s o l}\left(d_{a}\right)^{3}-1} .
$$

Here, $g_{\varepsilon}$ is the diameter growth factor of a particle consisting of an insoluble part and a volume fraction $\varepsilon$ of the model solute. $g_{\text {sol }}$ is the growth factor of a fully soluble $(\varepsilon=1)$ particle composed entirely of the same solute material, calculated according to

$g_{s o l}=\sqrt[3]{1+\frac{\rho_{s}}{\rho_{w} \eta\left(a_{w}\right) M_{s}}}$.

$\rho_{s}$ is the density of the salt and $\eta\left(a_{w}\right)$ the molality (moles of solute per $\mathrm{kg}$ of water). In order to take the Kelvin effect properly into account when calculating $\varepsilon, g_{s o l}$ should be calculated at the same humidified size $\left(d_{a}\right)$ as the observed particle (Swietlicki et al, 1999). If this effect is not taken into account, $\varepsilon$ is underestimated, especially for particles with $\varepsilon \cong 0.5$ and diameters below $100 \mathrm{~nm}$. From $\varepsilon$ the number of soluble molecules/ions can then be calculated as

$n_{i}=\varepsilon \cdot \frac{\pi \cdot d_{s}^{3}}{6} \cdot v \cdot \frac{\rho_{s}}{M_{s}}$.

Here, $d_{s}$ is the particle dry size.

Making a salt assumption in the calculations of $\varepsilon$ and $n_{i}$ does not imply that compounds other than the assumed 
salt, for example organic compounds, do not influence the particle-water interaction, but simply that all soluble molecules/ions are represented by the behavior of the model salt. Furthermore, the exact values of dry solute density $\rho_{s}$ and mole weight $M_{s}$ are irrelevant for CCN predictions using Eq. (4) since $\rho_{s}$ and $M_{s}$ are also implicitly included in Eq. (5) and explicitly in Eq. (7), and the effect on $n_{i}$ of changing $\rho_{s}$ and $M_{s}$ cancels out for ideal as well as non-ideal solutions. The same salt assumption used to calculate $\varepsilon$ has to be used when calculating $s_{c}$. The sensitivity of the predicted CCN concentration to the assumption of chemical composition will be discussed in the sensitivity study.

Using the relation in Eq. (7), with rearrangements, equation 4 becomes:

$$
\ln S_{c}=\left(E \cdot F \cdot \frac{\sigma_{w}^{3}}{d_{s}^{3}}\right)^{1 / 2} \approx s_{c},
$$

with

$$
E=4 \cdot\left(\frac{4}{3 R T}\right)^{3} \cdot\left(\frac{M_{w}}{\rho_{w}}\right)^{2} ; \quad F=\frac{M_{s}}{\varepsilon v \rho_{s}} .
$$

Equation (8) relates the particle diameter of the dry solute particle to its critical water vapor supersaturation, so that $s_{c}^{2}$ is proportional to $1 /\left(\varepsilon d_{s}^{3}\right)$, and also to $\sigma_{w}^{3}$.

The Köhler curve in the form of equation 1 is valid for dilute ideal solutions for which Raoult's law is applicable. The non-ideal behavior of the solute can be considered (in the sensitivity study), by substituting the dissociation factor, $v$ with the van't Hoff factor, $i$, in Eq. (3). When using the surface tension of pure water, $\sigma_{w}$, the possible influence of surface-active compounds is not taken into account. $n_{i}$, can however include all water-soluble compounds, also organic.

From Eqs. (4) and (8) it can be seen that the critical supersaturation only depends on $n_{i}$, or alternatively $\varepsilon$. Both these quantities can be obtained from the H-TDMA data. This way, $\varepsilon$ or $n_{i}$, and accordingly the critical supersaturation, are predicted for each dry size measured with the H-TDMA. According to Eq. (8), the relationship between the critical supersaturation $s_{c}$ and the dry activation diameter $d_{s}$ is log-log linear for a constant $\varepsilon$. In our measurements $\varepsilon$ changed only slightly with size, and consequently the estimated relationship between $s_{c}-d_{s}$ is approximately log-log linear. To obtain the dry activation diameter as a continuous function of supersaturation $s_{c}$, a linear interpolation is made after taking the logarithm of both $d_{s}$ and $s_{c}$. Particles with dry sizes above this diameter are expected to act as CCN. The CCN concentration is obtained by integrating the size distribution above the activation diameter.

The number of soluble molecules/ions contained in each dry particle as function of particle dry size, $n_{i}\left(d_{s}\right)$, can also be estimated from a chemical analysis, without using $\mathrm{H}$ TDMA data. The advantage of using the H-TDMA data for this purpose is the superior resolution in time and size. This is particularly important in clean environments where long sampling times are required to get above detection limits for the subsequent chemical analysis. It is also difficult to achieve an adequate chemical analysis of all water-soluble species, particularly the soluble organic species.

\subsection{Modal distribution and time resolution}

The CCN calculations were repeated for each DMPS size distribution, taken every $10 \mathrm{~min}$. Each H-TDMA dry size was measured approximately once every hour, and showed a rather stable hygroscopic growth behavior (Fig. 2b). The DMPS size distribution variability thus accounted for most of the temporal variability in the predicted $\mathrm{CCN}$ concentrations. The activation diameter, calculated for each complete H-TDMA scan, was linearly interpolated in time to match the DMPS time resolution.

For the cases when the H-TDMA measurements showed more than one single group of hygroscopic behavior, the $\mathrm{CCN}$ calculation was carried out for each hygroscopic group separately and summed. The aerosol fraction of the different modes was taken from the H-TDMA measurements, and linearly interpolated in time and particle dry size. For particle diameters outside the range of the H-TDMA observations $\left(d_{s}<20 \mathrm{~nm}\right.$ or $\left.d_{s}>265 \mathrm{~nm}\right), \varepsilon$ and the aerosol fraction in each mode was set to the values measured for the smallest or largest diameter, respectively.

\section{Submicron physical properties}

The field data used for the $\mathrm{CCN}$ prediction and closure study will be presented first. The analysis was carried out on the basis of the DMPS and H-TDMA data, together with meteorological information, air mass back trajectories and satellite images. To further establish the baseline conditions, the measured physical properties (size distribution and hygroscopic properties) were compared to those observed during the wet season in 1998 (Zhou et al., 2002). A comparison of particle physical properties between a clean period and periods under the influence of recent and aged biomass burning was made in order to identify changes in properties of the atmospheric aerosol due to biomass smoke. This provides the basis for further discussions of how the critical parameters used in the $\mathrm{CCN}$ predictions vary with different air masses, and how human activities affect the CCN properties.

\subsection{Air mass classification}

The purpose of the classification of the acquired data was to define the aerosol physical properties that are typical of certain types of air masses. Three time periods were selected for further scrutiny; they were chosen to represent the following air masses encountered during the wet-to-dry transition period: 

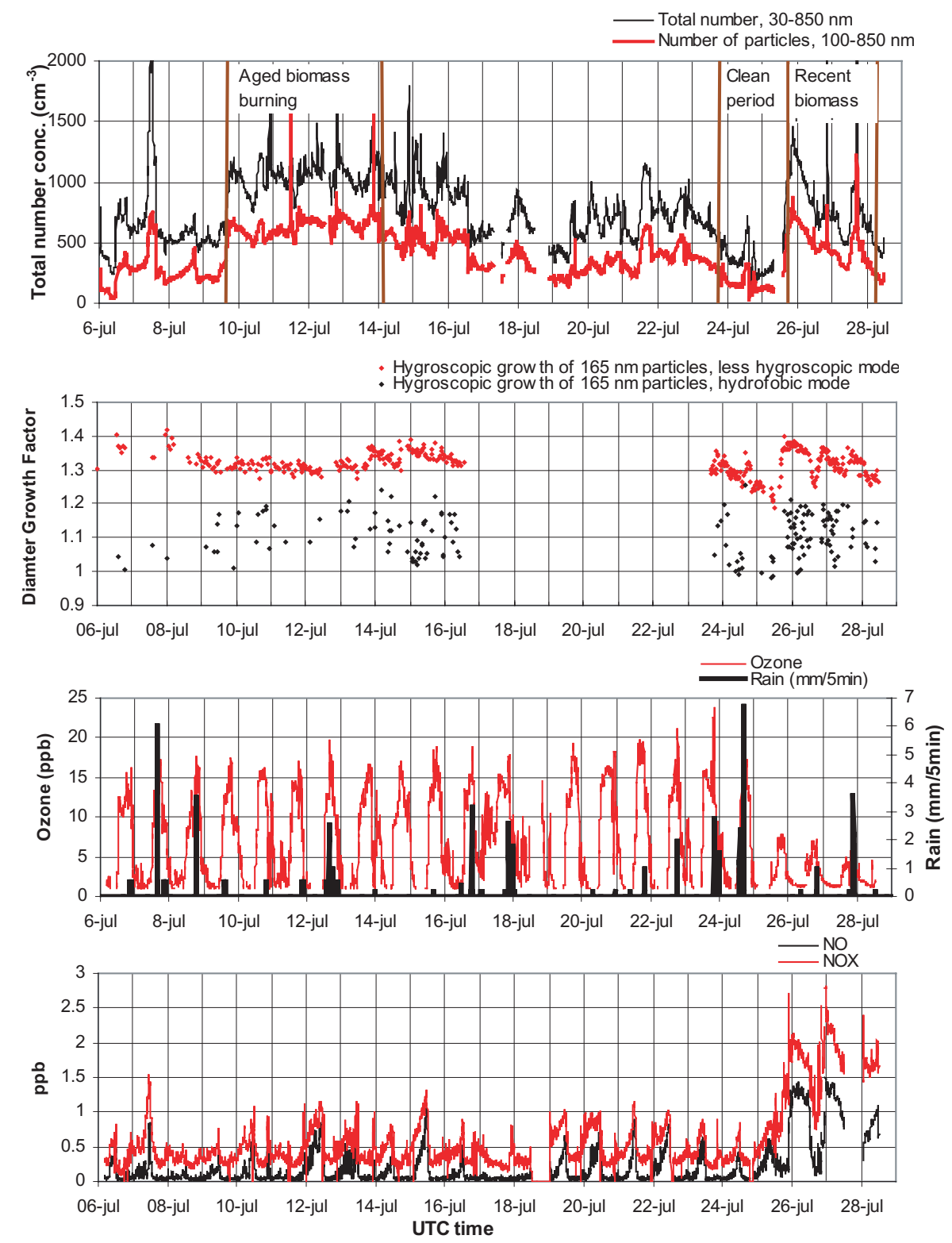

Fig. 2. Plots showing the time variation of particle and gas concentrations, hygroscopic properties and rain events. The figure also shows the periods selected for closer analysis. The time scales are given in UTC (=local time $+4 \mathrm{~h})$.

1. Clean background conditions over the rain forest,

2. Recent yet moderate influence from biomass burning superimposed on background air,

3. Aged biomass burning smoke.

The air masses representing clean background and aged biomass burning smoke are well defined and can be generalized to be valid for larger regions of the Amazon. The aged plume could be studied after it had crossed an otherwise clean area of the Amazon, with only few sources of recently emitted particles. Such conditions are encountered quite frequently in the atmosphere over the remote Amazon during the burning season, when smoke from the burning regions along the perimeter of the rainforest is transported over long distances into the pristine parts of the basin (e.g. Andreae et al., 1988). The observations made on recent biomass burning injected into a clean background air mass should be used with more care since the source was local and rather small.

The selection of time periods and air mass type was based on supporting data concerning gases $\left(\mathrm{NO}, \mathrm{NO}_{\mathrm{x}}, \mathrm{O}_{3}\right)$, meteorology (air mass back trajectories), remote sensing (fires in Brazil), and aerosol properties (Aethalometer Equivalent Black Carbon). In addition, PM0.85 aerosol mass and total number concentrations for particles larger than $30 \mathrm{~nm}$ were 
used. Both these quantities were derived from DMPS size distribution data, with PM0.85 calculated assuming spherical particles with a density of $1 \mathrm{~g} \mathrm{~cm}^{-3}$. The aerosol chemical data unfortunately had too poor a time resolution to be used for classification purposes. The sources of data other than from the DMPS, H-TDMA and CCN are listed in the acknowledgements.

Equivalent Black Carbon $\left(\mathrm{BC}_{e}\right)$ concentrations were measured with an Aethalometer (Magee Scientific, Berkeley, California), which monitors the light absorption by aerosol deposited on a quartz filter through which sample air is pumped at a flow rate of $20 \mathrm{~L} \mathrm{~min}^{-1}$, with a time resolution of $15 \mathrm{~min}$. A cross-section of $10 \mathrm{~m}^{2} \mathrm{~g}^{-1}$ was used to convert from light absorption to $\mathrm{BC}_{e}$ in units of $\mathrm{ngC} \mathrm{m}^{-3}$.

When comparing the data presented here with other measurements in air masses influenced by biomass burning, it should be kept in mind that the CLAIRE-2001 experiment was performed during the wet-to-dry season transition, in an area with pristine rainforest. The Balbina site was therefore not influenced by heavy plumes from intense biomass burning such as those encountered regularly during the dry season (Reid et al., 1998 (SCAR-B) and Vestin et al., 2004 (SMOCC)). Furthermore, the measurement site was situated in a forested area, while most biomass burning characterization experiments have been carried out in regions with ongoing rapid deforestation or already deforested regions such as the central part of Rondônia state. The particle concentrations observed during CLAIRE-2001 were therefore low compared to studies in regions with intense biomass burning.

\subsubsection{Clean period}

During the clean period ( 23 July $\sim 15: 00$ to 25 July $\sim 08: 00$, UTC), very low concentrations were observed for $\mathrm{BC}_{e}$ $\left(42 \pm 20 \mathrm{ng} \mathrm{m}^{-3}\right)$, particle number concentrations for particles larger than $30 \mathrm{~nm}\left(353 \pm 116 \mathrm{~cm}^{-3}\right)$, and PM0.85 particle mass $\left(0.68 \pm 0.28 \mu \mathrm{g} \mathrm{m}^{-3}\right)$.

No indications of pyrogenic NO were seen during this period. Daytime NO concentrations were near or below the detection limit $(0.025 \mathrm{ppb})$ as biogenic $\mathrm{NO}_{\mathrm{x}}$ is mixed upwards into a clean boundary layer, while nighttime NO concentrations often showed a steady increase from sunset until dawn (maximum $0.8 \mathrm{ppb}$ ) typical of $\mathrm{NO}$ emissions from the biota into a shallow nocturnal stable layer with weak sinks (Ganzeveld et al., 2002). After sunrise, the nocturnal inversion dissipated, and ozone entrained from the residual layer aloft efficiently converted the biogenic $\mathrm{NO}$ to $\mathrm{NO}_{2}$ (Fig. 2).

According to back trajectories, the air mass originated from ENE, moving in from the Atlantic over the Amazon delta and passing over $1000 \mathrm{~km}$ of pristine and virtually unpopulated rain forest before reaching the measurement site (Fig. 1). These trajectories did not pass over any of the areas with strong biomass burning that was observed by satellite remote sensing (satellites NOAA12 and 14, processed by INPE, Brazil). In fact, the clean period started when the trajectories at 500 and $1500 \mathrm{~m}$ levels (arrival height at the site) shifted from the biomass burning regions in the states of Maranhão, Goiás, Piauí, Ceará and Pará, to the Atlantic Ocean. The trajectories at the $3000 \mathrm{~m}$ arrival height stayed above $2500 \mathrm{~m}$, which is above the typical boundary layer height.

During CLAIRE-2001, only a short time period with such clean conditions could be identified. The main reason was that this experiment was specifically designed to study the transition between the wet (clean) and dry (biomass burning) seasons, which is a gradual process.

\subsubsection{Recent biomass burning period}

While the measurement site was still influenced by the clean background air mass (25 July, 15:00 UTC), burning of dry grass took place nearby (close to a small community $\sim 5 \mathrm{~km}$ from the Balbina site). This made it possible to study a recent (up to some hours old) biomass burning plume superimposed on a clean air mass with no, or at least only minor, influence from more aged pollution aerosol. The characteristic smell of biomass burning was noted and $\mathrm{NO}_{\mathrm{x}}$ concentrations increased significantly.

At the onset of biomass burning ( 11:00 local time), $\mathrm{O}_{3}$ concentrations decreased, indicating that it was being consumed by freshly emitted pyrogenic NO. NO levels remained fairly low until sunset when $\mathrm{O}_{3}$ concentrations fell below $2 \mathrm{ppb}$, and NO concentrations suddenly rose to about $1.3 \mathrm{ppb}$, clearly indicating a very fresh smoke plume (Fig. 2).

$\mathrm{BC}_{e}$ and particle number concentrations also showed an increase (from $\sim 30 \mathrm{ng} \mathrm{m}^{-3}$ and $\sim 500 \mathrm{~cm}^{-3}$ respectively) to $158 \pm 55 \mathrm{ng} \mathrm{m}^{-3}$ and $1230 \pm 499 \mathrm{~cm}^{-3}$ respectively (average taken over the recent biomass burning period; 25 July 15:00 to 28 July 04:00 UTC), indicating a moderately polluted air mass. A change in hygroscopic properties was also seen on this occasion (Fig. 2). PM0.85 particle mass was $1.94 \pm 0.61 \mu \mathrm{g} \mathrm{m}^{-3}$.

\subsubsection{Aged biomass burning period}

An airmass with considerably more aged biomass smoke ( 9 July $\sim 16: 00$ to 13 July $\sim 24: 00$, UTC) could be studied during a contiguous time period with stable meteorological conditions and elevated particle mass concentrations. For several reasons, this period was interpreted to be representative of aged biomass smoke.

At the onset of the aged biomass smoke period (9 July, $\sim 16: 00$ UTC), the origins of the $500 \mathrm{~m}$ level (arrival height at the site) trajectories shifted from the Atlantic Ocean to the biomass burning region in the states of Maranhão, Goiás, Piauí, Ceará and eastern parts of Pará. Fires were frequently detected within these states by satellite remote sensing (NOAA12 and NOAA14) (Fig. 1). The transport time from the biomass burning source region to the Balbina site was $2.5-5$ days. No fires were seen by satellite remote 
Table 2. Statistics of the particle number size distribution. Each DMPS spectra was fitted with two or three log normal distributions. "Nucleation fit av." represents the result when fitting the average spectra. "Frequency of occurrence" is in that case referring to the frequency when number concentration for particles $<30 \mathrm{~nm}$ exceeded $60 \mathrm{~cm}^{-3}$. Resulting average for CLAIRE-98 is presented in Table 5 and Zhou et al. (2002).

\begin{tabular}{|c|c|c|c|c|c|c|}
\hline \multirow[t]{2}{*}{ Mode } & \multirow{2}{*}{$\begin{array}{l}\text { Frequency of } \\
\text { occurrence (\%) }\end{array}$} & \multicolumn{3}{|c|}{ Number concentration $\left(\mathrm{cm}^{-3}\right)$, when present } & \multirow{2}{*}{$\begin{array}{l}\text { Geom. Mean diameter, } \\
\text { when present }(\mathrm{nm})\end{array}$} & \multirow{2}{*}{$\begin{array}{l}\text { Geom. Standard deviation, } \\
\text { when present }\end{array}$} \\
\hline & & Mean \pm s.d. & Geom. mean & Median & & \\
\hline \multicolumn{7}{|c|}{ Clean period $(\mathrm{n}=226)$} \\
\hline Accumulation & $100 \%$ & $176 \pm 91$ & 149 & 153 & $145 \pm 18$ & $1.41 \pm 0.07$ \\
\hline Aitken & $100 \%$ & $167 \pm 76$ & 151 & 153 & $70 \pm 9$ & $1.34 \pm 0.17$ \\
\hline Nucleation & $79 \%$ & $191 \pm 270$ & 107 & 105 & $17 \pm 5$ & $1.32 \pm 0.25$ \\
\hline Nucleation, fit av. & $80 \%$ & 160 & & & 13.5 & 1.8 \\
\hline \multicolumn{7}{|c|}{ Recent biomass burning ( $\mathrm{n}=320)$} \\
\hline Accumulation & $100 \%$ & $529 \pm 216$ & 478 & 512 & $148 \pm 11$ & $1.43 \pm 0.06$ \\
\hline Aitken & $100 \%$ & $280 \pm 181$ & 255 & 251 & $69 \pm 9$ & $1.35 \pm 0.19$ \\
\hline Nucleation & $59 \%$ & $302 \pm 340$ & 201 & 194 & $14 \pm 5$ & $1.31 \pm 0.20$ \\
\hline Nucleation, fit av. & $82 \%$ & 315 & & & 11 & 1.75 \\
\hline \multicolumn{7}{|c|}{ Aged biomass burning ( $\mathrm{n}=562)$} \\
\hline Accumulation & $100 \%$ & $736 \pm 159$ & 641 & 760 & $139 \pm 7$ & $1.45 \pm 0.04$ \\
\hline Aitken & $100 \%$ & $304 \pm 184$ & 244 & 250 & $68 \pm 9$ & $1.32 \pm 0.14$ \\
\hline Nucleation & $55 \%$ & $276 \pm 290$ & 163 & 185 & $15 \pm 9$ & $1.29 \pm 0.22$ \\
\hline Nucleation, fit av. & $68 \%$ & 310 & & & 12.7 & 1.7 \\
\hline
\end{tabular}

sensing along the track of the lowest level trajectories with transport times shorter than 2.5 days.

The end of the period (13 July, 24:00 UTC) was set to the time when the lowest trajectory again moved out over the Atlantic Ocean. Trajectories at higher arrival heights followed the same general pattern, but were in general more shifted towards the biomass burning region. Even though the elevated particle concentrations persisted until 16 July at $\sim$ 14:00 UTC, the concentrations were somewhat higher during the selected period, and the size distributions were quite stable over time (Fig. 3). This stability, in both the shape of the size distributions and the concentrations, implies that the aerosol was well mixed up to the altitude of the maximum daytime boundary layer height $(\sim 1500 \mathrm{~m})$, since consistent diurnal variations would otherwise have been observed.

$\mathrm{BC}_{e}$ and particle number concentrations averaged over the aged biomass burning period were $208 \pm 53 \mathrm{ng} \mathrm{m}^{-3}$ and $1353 \pm 435 \mathrm{~cm}^{-3}$, respectively. PM0.85 particle mass was $2.34 \pm 0.35 \mu \mathrm{g} \mathrm{m}^{-3}$. $\mathrm{NO}_{\mathrm{x}}$ concentrations were only slightly higher than during the clean period, most likely a result of the short atmospheric residence time of $\mathrm{NO}_{\mathrm{x}}(\sim 1$ day). Again, this is consistent with aged smoke (Andreae and Merlet, 2001). For both polluted time periods, the filter sample analysis showed the presence of potassium, a compound used typically as tracer for biomass burning (Andreae, 1983, Yamasoe et al., 2000 Artaxo et al. 1998).

\subsection{Submicron physical properties}

\subsubsection{Submicron size distribution $(3-850 \mathrm{~nm})$}

The submicrometer particle number concentrations observed during CLAIRE-2001 generally exceeded those measured at the same site in 1998. The number concentrations typically fluctuated around $1000 \mathrm{~cm}^{-3}$ (Fig. 2), with median and average particle concentrations during the entire campaign of 984 and $1080 \mathrm{~cm}^{-3}$ respectively, compared to $\sim 400 \mathrm{~cm}^{-3}$ in 1998. This result was expected, since the 1998 campaign was performed entirely within the wet season, with no biomass burning taking place, and more efficient rain- and wash-out due to intense precipitation.

The average number size distributions for the three time periods selected can be seen in Fig. 3 together with the temporal variability ( \pm 1 s.d.) at each measured particle diameter. Each individual DMPS number size distribution was fitted with 2 or 3 lognormal distributions, resulting in three parameters for each mode: integral number, geometric mean diameter and geometric standard deviation. Table 2 presents the fitted parameters for the three different air mass categories separately. The particle size distribution was always bimodal in the size interval 30-850 nm with an Aitken $(0.03-0.1 \mu \mathrm{m})$ and accumulation mode $(0.1-1 \mu \mathrm{m})$ present.

When comparing the average size distribution only for the 2001 clean period with that of the wet season in 1998, similar distributions and concentrations were found (Fig. 3 

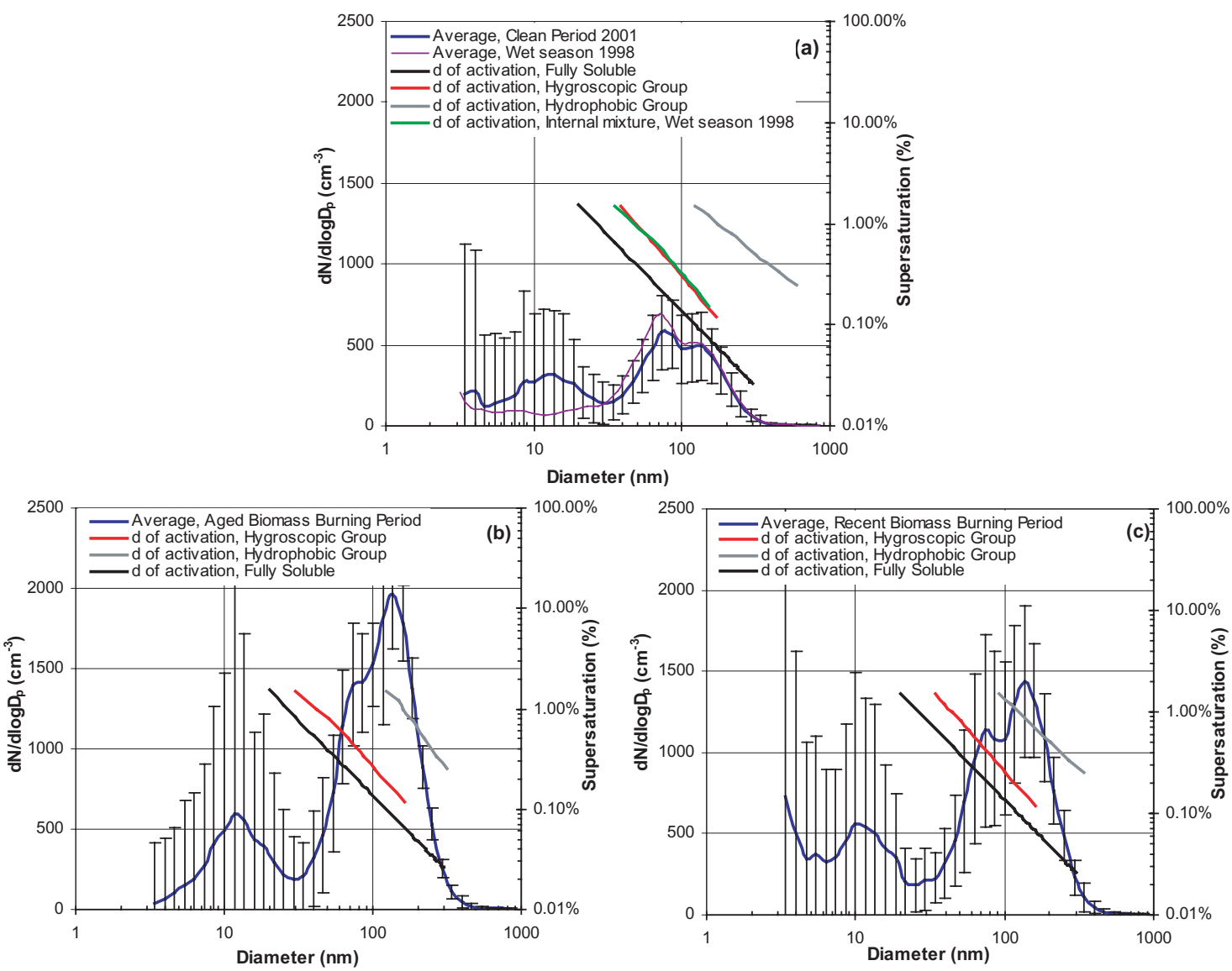

Fig. 3. The average size distributions for the selected time periods together with the $d_{a c t}$ as a function of critical supersaturation. The error bars depict the temporal variability ( \pm 1 s.d.) for each size measured.

and Table 5), the major differences being that in 2001, the number concentrations in the Aitken mode size range were slightly lower, and nucleation $(<30 \mathrm{~nm})$ mode particles occurred more frequently.

The recent biomass burning plume was estimated to be only some hours old, and despite the relatively short distance between the fires and the measurement site, the average number concentration was quite low at $1230 \pm 499 \mathrm{~cm}^{-3}$. The size distributions were narrow and bimodal, but when subtracting the size distribution of the background aerosol, the Aitken mode diminished in importance relative to the accumulation mode. The size distribution of the superimposed recent biomass burning aerosol became nearly unimodal, centered around $135 \mathrm{~nm}$.

The measured concentrations were lower and shifted towards lower sizes than the concentrations observed during the SCAR-B (Reid et al., 1998) and SMOCC (Vestin, 2003) field experiments in Rondônia located in the SW Amazon region. However, those field experiments were carried out during periods with intense biomass burning activities covering large areas. It should be stressed that CLAIRE-2001 was performed at a site with pristine rainforest and that biomass burning activities were very limited in the region encompass- ing the nearest $500 \mathrm{~km}$ or so, even during the dry period. The recent plume observed during CLAIRE-2001 originated from residential burning of branches and grass. Comparing the measured size distribution with that measured with a PCASP (Passive Cavity Aerosol Spectrometer Probe) during flight measurements over the savannah in the southern Africa (SAFARI, Haywood et al., 2003), the distributions were similar. The plume measured in CLAIRE 2001 had a slightly wider peak and slightly shifted towards lower sizes. For the SAFARI flight measurements biomass fires dominate the source. Studies of emissions from combustion of biomass show large variability in the emitted particle size distributions (e.g. Christensen et al., 1998; Hedberg et al., 2002; Pagels et al., 2003), showing quite narrow as well as somewhat broader and even bimodal size distributions, depending on type of fuel, fuel moisture and burning conditions.

During the aged biomass burning period, the number concentrations were elevated compared to the clean background air mass by nearly a factor of 2 in the Aitken mode size range, and 4-5 times in the accumulation mode size range. The median total number concentration was $1230 \mathrm{~cm}^{-3}$ (average $1350 \mathrm{~cm}^{-3}$ ), dominated by the accumulation mode particles. 
The size distribution in this air mass was also narrow compared to dry season regional haze (Swietlicki et al., 2003). This is most likely the result of atmospheric processing and wet deposition. Even though the regional haze particles are only moderately hygroscopic (Swietlicki et al., 2003), particles with diameters $>\sim 100 \mathrm{~nm}$ are easily activated in cumuliform clouds. These particles are therefore also efficiently removed by wet deposition, thus reducing number concentrations in the entire accumulation mode size range. They are replaced by particles from the Aitken mode that may grow either outside clouds by coagulation or condensation, which are rather slow processes, or more efficiently during the cycling through non-precipitating clouds. This process is believed to be responsible for forming the so-called Hoppel minimum, denoting the frequently observed dip in the number size distribution separating the Aitken and accumulation modes (Hoppel et al., 1994). The resulting size distribution after ageing would be expected to show such a Hoppel minimum, and rather narrow Aitken and accumulation modes (Raes et al., 2000). The narrow and bimodal distribution of the aged aerosol is therefore most likely the result of atmospheric processing of regional haze particles during several days.

\subsubsection{The nucleation mode}

The nucleation mode (here defined as particles of diameters $<30 \mathrm{~nm}$ ) was highly variable and often without any clear modal structure. It was therefore difficult to fit this mode with a log-normal distribution. The fitting was nevertheless carried out whenever possible to provide additional statistics on the presence of these particles (Table 2). When applying instead a criterion of number concentrations above $60 \mathrm{~cm}^{-3}$ for particle diameters $<30 \mathrm{~nm}$, the nucleation mode particles were present in $71 \%$ of all cases, compared to $44 \%$ of the cases observed during the wet season in 1998. When the same limit $\left(60 \mathrm{~cm}^{-3}\right)$ is applied to the selected time periods, then nucleation mode particles were present in $80 \%$ of the cases during the clean period, in $68 \%$ of the cases during the aged biomass burning period, and in $82 \%$ of the cases during the recent biomass burning period. The frequencies of occurrence for the fitted nucleation mode are somewhat lower (Table 2).

Due to both the difficulties in fitting, and the high variability of the size and concentration of the nucleation mode particles, two parameterizations of the nucleation mode statistics are presented in Table 2. The first is based on separate log-normal fits to each measured distribution, while the other describes the properties of a log-normal distribution fitted to the average size distribution for each selected time period, as presented in Fig. 3. The fit to the average size distribution was much wider than the nucleation mode parameterization for the individual distributions, and shifted towards smaller sizes. The reason for this is, that, even though the individual nucleation mode fits are quite narrow, the count median diameter varies considerably within the interval $3-30 \mathrm{~nm}$ interval, which smears out the average distribution.

Even though particles could be detected down to $3 \mathrm{~nm}$ in diameter, particles appeared only sporadically in the lowest size range of the nucleation mode at ground level. Since new particle formation from homogeneous nucleation of gas phase precursors produces particles with critical cluster diameters on the order of $1 \mathrm{~nm}$ (Kulmala et al., 2000), which then grow rapidly into the detectable size range $(>3 \mathrm{~nm})$ it can be concluded that in general, no nucleation events were taking place in the immediate vicinity of the site itself. The absence of nucleation events is consistent with the observations made during the wet season CLAIRE-1998 experiment, and the hypothesis proposed by Zhou et al. (2002) that the nucleation mode particles were mostly formed at somewhat higher altitudes and brought down to ground level by vertical mixing, or that the particles were being formed as a result of the mixing process itself.

The nucleation mode most often had a daily variation, appearing strongly around 16-18 local time (LT), remaining present for some hours, then decreasing or disappearing to increase again in the early morning around 6-7 LT. At around 9-10 LT the mode disappeared and stayed absent until the evening. The time when the particles appeared in the morning was more consistent than in the evening. The nucleation mode thus seemed to be present around the inversion breakup in the morning (correlated with sudden decrease of $\mathrm{CO}_{2}$ ), appeared again when the inversion started to build up in the evening, and was frequently present during the night. Another connection that was seen was particles appearing contemporaneously with heavy rain at the site or close by, which often occurred in the early evenings.

\subsubsection{Hygroscopic properties of submicron particles}

The CLAIRE-2001 H-TDMA data were classified into groups of particles with different hygroscopic behavior, in accordance with previous observations of hygroscopic properties in various environments. The groups were denoted hydrophobic, less-hygroscopic, and more-hygroscopic. This classification also defines the degree of external mixture from a hygroscopicity point of view, and is based on the observed growth factors, which can be recalculated as soluble volume fractions $(\varepsilon)$ of the individual particles. The soluble volume fraction $(\varepsilon)$ is calculated according to the description made in Sect. 3, using ammonium hydrogen sulfate to represent the soluble fraction.

The hydrophobic particle group contains very little soluble material, $0<\varepsilon<0.12$ for $165 \mathrm{~nm}$ particles and smaller, with $\varepsilon=0.18$ taken as an upper limit for the hydrophobic 265 $\mathrm{nm}$ particles. This corresponds to diameter growth factors (from dry to RH=90\%) between 1 and 1.13-1.17. Particles classified to the less-hygroscopic group had growth factors between this value and $\sim 1.5(0.12<\varepsilon<0.5)$, while the morehygroscopic particles had growth factors $>\sim 1.5(\varepsilon>0.5)$. 
Exceptions from the classification rules were made in a limited number of cases when the rules could not be strictly obeyed. In these cases, the particles with the smallest growth factor were classified as hydrophobic.

Using this classification, more-hygroscopic particles were only observed in $1 \%$ of the measurements made, compared to 3-9\% during CLAIRE-98. The less-hygroscopic particle group was ubiquitous in the Aitken and accumulation mode size ranges. This group also completely dominated the number concentration for all measured dry sizes (with the exception of $30 \mathrm{~nm}$ particles). Hydrophobic particles were present in $51 \%$ of all scans, and were more prominent at the smallest and largest particle sizes $(30-35 \mathrm{~nm}$ and $265 \mathrm{~nm})$ relative to the less-hygroscopic mode. The H-TDMA observations are summarized in Table 3, and an example of the temporal variation in hygroscopic growth factors (for $165 \mathrm{~nm}$ particle dry size) is shown in Fig. 2.

As for the number size distributions, good agreement was found between the hygroscopic properties observed during the CLAIRE-2001 clean period and the 1998 wet season experiment. The major difference was that hydrophobic particles were more frequent in 2001 (25-49\% of all cases, depending on particle dry size) compared to 1998 (5-14\%). The growth factors were very similar during both experiments.

An increase in hygroscopicity was observed for the period influenced by recent biomass burning (Fig. 2). A possible explanation for the increased hygroscopicity is that the burning of branches and grass can reach high temperatures and be burnt with high efficiency. This would produce particles with smaller mass fractions of organic material and soot, and more of the hygroscopic potassium salts. The chemical composition of particles formed in biomass burning is very much dependent on the material being burnt and the conditions of combustion. Hygroscopic growth factors as high as 1.8 (dry to $\mathrm{RH}=90 \%$ ) have been reported for sub-micrometer particles emitted from $\sim 1 \mathrm{MW}$ biomass combustion units in Sweden (Pagels et al., 2003). During the recent biomass burning period, hydrophobic particles were also observed in an external mixture. These particles were probably formed during the smoldering phase. The hydrophobic particles were more frequent during the occasions with recent biomass burning than otherwise.

During some days, RH was scanned for a fixed particle size, in order to see if the estimated $\varepsilon$ was dependent on RH. This may be the case when poorly soluble compounds were present at $\mathrm{RH}=90 \%$. Alternatively, the non-ideal behavior of the model compound may differ from that of the solute assumed, manifesting itself in an $\varepsilon$ that varies slightly with $\mathrm{RH}$. The RH scans indicated that $\varepsilon$ did not increase with RH above $\sim 80 \%$ RH. No deliquescence behavior was observed.

\section{CCN prediction}

Predictions of CCN concentrations can be made using various model approaches, but all rely on descriptions of the Raoult and Kelvin terms of the Köhler equation (Brechtel and Kreidenweis, 2000a, b; Covert et al., 1988; VanReken et al., 2003; Cantrell et al., 2001; Snider et al., 2003). Here, the $\mathrm{CCN}$ number concentrations were predicted from direct observations of the key aerosol physical properties; the 3$850 \mathrm{~nm}$ number size distributions measured with a DMPS, and the amount of soluble material present in individual particles derived from the H-TDMA measurements. An approximation of the Köhler equation, focusing on the number of soluble molecules/ions available for condensation of water vapor, was applied to estimate the minimum particle diameter that activates, $d_{a c t}$, at a given supersaturation (see Sect. 3). All soluble material available at the point of activation is assumed to already be in solution at $\mathrm{RH}=90 \%$.

In the first sensitivity study, three different salts were applied, one at a time, to investigate the sensitivity of the CCN predictions to the selection of the inorganic model compound. The inorganic salts used were ammonium hydrogen sulfate $\left(\mathrm{NH}_{4} \mathrm{HSO}_{4}\right)$, ammonium sulfate $\left(\left(\mathrm{NH}_{4}\right)_{2} \mathrm{SO}_{4}\right)$ and potassium chloride $(\mathrm{KCl})$. The first two salts are known to be main soluble components of the background atmospheric aerosols in the Amazon region (Roberts et al., 2002; Gerab et al., 1998), while potassium salts are components of the fine fraction aerosol particles emitted from biomass burning (Andreae, 1983; Yamasoe et al., 2000; Reid et al., 1998; Hedberg et al., 2002).

In addition, a more complicated model compound was used: the particle soluble volume fraction was assumed to consist of a mixture of ammonium sulfate (30\% by mass), levoglucosan (18\%), succinic acid (25\%) and fulvic acid (27\%), representative of an aerosol from biomass burning (denoted MIXBIO; Svenningsson et al., 2004 ${ }^{1}$ ). Levoglucosan is a pyrolysis product of cellulose, and has been found in high concentrations (several percent by mass) in biomass burning aerosols (Simoneit et al., 1999). Succinic acid is a moderately soluble dicarboxylic acid, while fulvic acid is not a well-defined chemical compound, but rather a mixture of several organic compounds with a large variability in molecular weight (Decesari et al., 2000). The hygroscopic behavior of all model compounds and the mixture was determined in the laboratory using an H-TDMA instrument identical to that used during the CLAIRE-2001 field experiment (Svenningsson et al., $2004^{1}$ ).

When estimating the soluble volume fraction from the hygroscopic growth observed at $\mathrm{RH}=90 \%$, a model compound

\footnotetext{
${ }^{1}$ Svenningsson, B., Rissler, J., Swietlicki, E., Mircea, M., Bilde, M., Facchini, C., Zhou, J., Monster, J., and Rosenorn, T.: Hygroscopic Growth and Critical Supersaturations for Mixed Aerosol Particles of Inorganic Compounds of Atmospheric Relevance, to be submitted to Atmos. Chem. Phys. Discuss., 2004.
} 
Table 3. Summary of the H-TDMA observations of hygroscopic growth at $90 \%$ RH during CLAIRE 2001 for the selected clean period, period with recent biomass burning and an aged biomass burning plume.

\begin{tabular}{|c|c|c|c|c|c|c|}
\hline \multirow{2}{*}{$\begin{array}{l}\text { Clean period } \\
\text { Growth factor at } 90 \% \mathrm{RH}\end{array}$} & \multicolumn{6}{|c|}{ Dry particle diameter } \\
\hline & $35 \mathrm{~nm}$ & $50 \mathrm{~nm}$ & $75 \mathrm{~nm}$ & 110nm & $165 \mathrm{~nm}$ & $265 \mathrm{~nm}$ \\
\hline Total number of observations & 72 & 79 & 79 & 77 & 76 & 74 \\
\hline \multicolumn{7}{|l|}{ Less-hygroscopic particles } \\
\hline frequency of occurrence & $100 \%$ & $100 \%$ & $100 \%$ & $100 \%$ & $100 \%$ & $100 \%$ \\
\hline growth factor (average \pm s.d.) & $1.14 \pm 0.06$ & $1.17 \pm 0.05$ & $1.20 \pm 0.04$ & $1.25 \pm 0.04$ & $1.28 \pm 0.03$ & $1.33 \pm 0.06$ \\
\hline number fraction (when present) & $0.89 \pm 0.21$ & $0.87 \pm 0.20$ & $0.95 \pm 0.12$ & $0.93 \pm 0.13$ & $0.96 \pm 0.08$ & $0.86 \pm 0.17$ \\
\hline Soluble volume fraction $\left(\mathrm{NH}_{4} \mathrm{HSO}_{4}\right)$ & $0.14 \pm 0.07$ & $0.15 \pm 0.05$ & $0.16 \pm 0.04$ & $0.20 \pm 0.04$ & $0.23 \pm 0.03$ & $0.27 \pm 0.06$ \\
\hline \multicolumn{7}{|l|}{ "Hydrophobic" particles } \\
\hline frequency of occurrence & $25 \%$ & $35 \%$ & $16 \%$ & $23 \%$ & $26 \%$ & $49 \%$ \\
\hline growth factor (average \pm s.d.) & $1.02 \pm 0.04$ & $1.07 \pm 0.04$ & $1.07 \pm 0.04$ & $1.08 \pm 0.05$ & $1.05 \pm 0.06$ & $1.15 \pm 0.07$ \\
\hline number fraction (when present) & $0.42 \pm 0.21$ & $0.34 \pm 0.21$ & $0.28 \pm 0.14$ & $0.28 \pm 0.12$ & $0.14 \pm 0.06$ & $0.28 \pm 0.11$ \\
\hline Soluble volume fraction $\left(\mathrm{NH}_{4} \mathrm{HSO}_{4}\right)$ & $0.03 \pm 0.03$ & $0.06 \pm 0.03$ & $0.05 \pm 0.03$ & $0.06 \pm 0.04$ & $0.04 \pm 0.05$ & $0.11 \pm 0.05$ \\
\hline
\end{tabular}

Recent Biomass burning,

moderate pollution

Growth factor at $90 \% \mathrm{RH}$

Dry particle diameter

Total number of observations

$35 \mathrm{~nm}$

$50 \mathrm{~nm} \quad 75 \mathrm{~nm} \quad 110 \mathrm{~nm}$

100

112

117

122

121

Less-hygroscopic particles

frequency of occurrence

growth factor (average \pm s.d.)

number fraction (when present)

(a)

Soluble volume fraction $\left(\mathrm{NH}_{4} \mathrm{HSO}_{4}\right)$

$1.18 \pm 0.04$

$100 \%$

$0.73 \pm 0.23$

$1.21 \pm 0.03$

$99 \%$

$1.30 \pm 0.03$
$0.86 \pm 0.13$

$165 \mathrm{~nm}$

$265 \mathrm{~nm}$

$0.18 \pm 0.05$

$0.19 \pm 0.03$

$0.82 \pm 0.17$

$0.26 \pm 0.03$

121

119

"Hydrophobic" particles

frequency of occurrence

growth factor (average \pm s.d.)

$74 \%$

$69 \%$

$0.22 \pm 0.03$

$1.03 \pm 0.04$

$68 \%$

$65 \%$

$1.09 \pm 0.05$

$58 \%$

$100 \%$

$100 \%$

number fraction (when present)

$0.37 \pm 0.22$

$1.04 \pm 0.04 \quad 1.07 \pm 0.05$

$0.37 \pm 0.20$

$0.28 \pm 0.17$

$0.23 \pm 0.13$

$1.12 \pm 0.05$

$0.19 \pm 0.08$

$0.04 \pm 0.03$

$0.05 \pm 0.04$

$0.07 \pm 0.04$

$0.09 \pm 0.04$

\begin{tabular}{|c|c|c|c|c|c|c|}
\hline \multirow{2}{*}{$\begin{array}{l}\text { Aged Biomass burning, } \\
\text { moderate pollution } \\
\text { Growth factor at } 90 \% \mathrm{RH}\end{array}$} & \multicolumn{6}{|c|}{ Dry particle diameter } \\
\hline & $30 \mathrm{~nm}$ & $50 \mathrm{~nm}$ & $75 \mathrm{~nm}$ & $110 \mathrm{~nm}$ & $165 \mathrm{~nm}$ & $265 \mathrm{~nm}$ \\
\hline Total number of observations & 56 & 92 & 92 & 95 & 97 & 91 \\
\hline \multicolumn{7}{|l|}{ Less-hygroscopic particles } \\
\hline growth factor (average \pm s.d.) & $1.21 \pm 0.06$ & $1.21 \pm 0.02$ & $1.24 \pm 0.02$ & $1.29 \pm 0.02$ & $1.31 \pm 0.02$ & $1.35 \pm 0.04$ \\
\hline number fraction (when present) & $0.45 \pm 0.32$ & $0.82 \pm 0.20$ & $0.94 \pm 0.11$ & $0.97 \pm 0.07$ & $0.96 \pm 0.08$ & $0.73 \pm 0.21$ \\
\hline Soluble volume fraction $\left(\mathrm{NH}_{4} \mathrm{HSO}_{4}\right)$ & $0.23 \pm 0.08$ & $0.20 \pm 0.03$ & $0.21 \pm 0.02$ & $0.25 \pm 0.02$ & $0.26 \pm 0.02$ & $0.29 \pm 0.05$ \\
\hline \multicolumn{7}{|l|}{ "Hydrophobic" particles } \\
\hline frequency of occurrence & $89 \%$ & $59 \%$ & $33 \%$ & $16 \%$ & $21 \%$ & $79 \%$ \\
\hline growth factor (average \pm s.d.) & $1.02 \pm 0.03$ & $1.03 \pm 0.03$ & $1.04 \pm 0.04$ & $1.08 \pm 0.06$ & $1.13 \pm 0.05$ & $1.15 \pm 0.06$ \\
\hline number fraction (when present) & $0.81 \pm 0.25$ & $0.32 \pm 0.20$ & $0.19 \pm 0.13$ & $0.16 \pm 0.07$ & $0.18 \pm 0.07$ & $0.34 \pm 0.17$ \\
\hline Soluble volume fraction $\left(\mathrm{NH}_{4} \mathrm{HSO}_{4}\right)$ & $0.02 \pm 0.03$ & $0.03 \pm 0.02$ & $0.03 \pm 0.03$ & $0.06 \pm 0.05$ & $0.10 \pm 0.04$ & $0.11 \pm 0.05$ \\
\hline
\end{tabular}




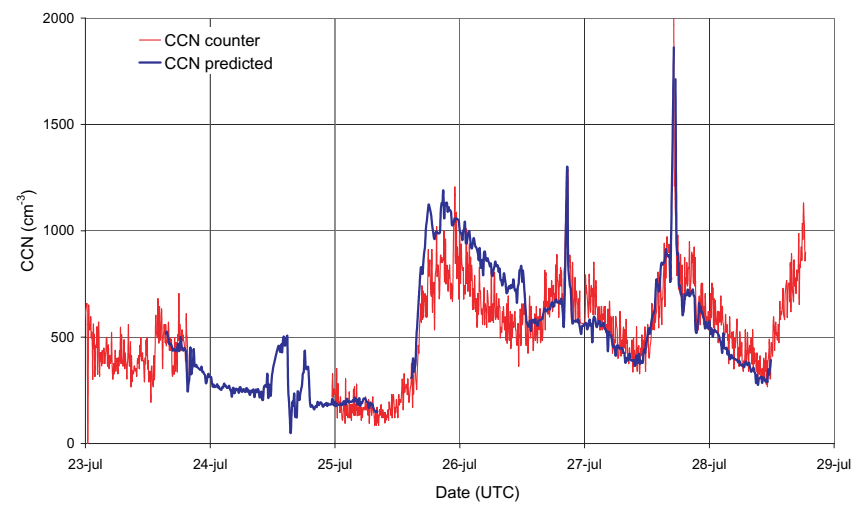

Fig. 4. A comparison between the predicted $\mathrm{CCN}$ concentration and the $\mathrm{CCN}$ concentration measured with a $\mathrm{CCN}$ counter for $0.66 \%$ supersaturation.

(or as in the latter case a mixture of model compounds) was assumed to be responsible for the condensation of water vapor. This does not mean that the specific model compound is solely responsible for the water uptake from the vapor phase, while all others are inactive. Instead, the single model compound is used to represent all soluble molecules/ions or molecules, inorganic or organic, that are available at the supersaturation at which activation takes place.

Organic surfactants have been shown to reduce the surface tension. The sensitivity study also included an investigation of the possible impact on the $\mathrm{CCN}$ concentrations of reducing the surface tension by $15 \%$ at the point of activation. This reduction was estimated by Roberts et al. (2002) to be a likely limit for the surface tension change in activating aerosol particles in the Amazon region.

\subsection{Modeled and measured CCN concentrations}

The calculations of CCN concentrations $\left(N_{C C N}\right)$ derived from DMPS and H-TDMA data were performed with 10 min time resolution, and for up to 19 different supersaturations in the range $s_{c}=0.12-1.5 \%$. Both the temporal variation $\left(N_{C C N}(t)\right)$ at a given supersaturation, as well as the continuous spectra for a specific time period as a function of supersaturation $\left(N_{C C N}\left(s_{c}\right)\right)$, was derived.

Since the aerosol appeared to be externally mixed, the $\mathrm{CCN}$ calculations were made for each hygroscopic mode separately. When determining the activation diameter, $d_{a c t}$, at a given supersaturation, $\mathrm{NH}_{4} \mathrm{HSO}_{4}$ was used as model salt representing the soluble molecules/ions. The non-ideality of the salt was taken into account at subsaturations, but at supersaturation the salt was assumed to behave ideally (this is discussed and investigated closer in the sensitivity study). In order to minimize a possible loss of information, the original DMPS size distribution data was used directly in the calculations instead of the fitted log-normal modal distributions.

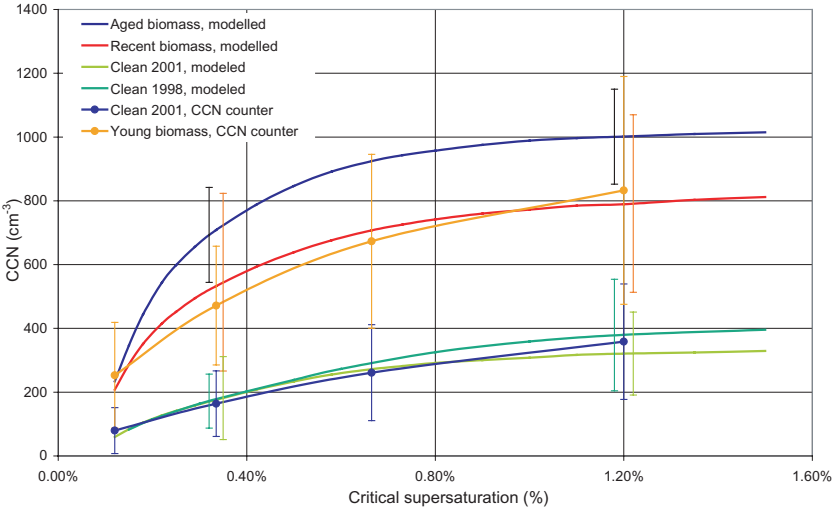

Fig. 5. The average $\mathrm{CCN}$ spectra for the three selected periods, as a function of supersaturation. Error bars represent \pm 1 s.d. (temporal variability). The differences in shape of the $\mathrm{CCN}$ spectra for the periods are mainly due to the size distributions (Fig. 3).

The predictions were made for the time periods for which H-TDMA data was available. The CCN counter was operating in parallel with the DMPS and H-TDMA during the clean period and the recent biomass burning period. During this period the $\mathrm{CCN}$ counter had a failure between 23 July 21:00-24 July 23:00. In the CCN closure, only the time periods during which all three instruments were running in parallel were used.

Figure 4 shows the measured and predicted $\mathrm{CCN}$ concentrations at $0.66 \%$ supersaturation during 23-28 July 2001. It is obvious that the actual measurements obtained with the $\mathrm{CCN}$ counter showed larger variability over shorter time periods $(\sim 1 \mathrm{~h})$ than did the predicted $\mathrm{CCN}$ concentrations. The temporal resolutions of both instruments were similar (DMPS: $10 \mathrm{~min}$; CCN counter: $6 \mathrm{~min}$ ). This somewhat deteriorates the covariation (Table 4) between predicted and measured $\mathrm{CCN}$ concentrations. One reason for this might be the $\mathrm{CCN}$ instrument error due to lack of precision, estimated to 20\% (Nenes et al., 2001a). Another feature seen in Fig. 4 is that $\mathrm{CCN}$ concentrations were slightly overpredicted during some periods (e.g. 25 July 15:00-26 July 12:00 UTC), while underpredicted during others (e.g. 26 July 12:00-28 July 04:00 UTC), even though the predictions track the overall measured concentrations well within each time period. The same behavior is seen for supersaturations of $0.33 \%$ and $1.2 \%$. To properly reproduce the $\mathrm{CCN}$ measurements at $0.33 \%, 0.66 \%$ and $1.2 \%$ supersaturation for the time period showing over predictions, the predicted activation diameters need to be increased from about 88 to $125 \mathrm{~nm}$, from 60 to $85 \mathrm{~nm}$, and from 42 to $60 \mathrm{~nm}$ respectively. This is outside the range of uncertainty for the DMPS and H-TDMA measurements alone. The reason for this discrepancy could not be determined. At $0.12 \%$ supersaturation, the correlation between the predicted and measured result is lower than for the 
Table 4. The correlation coefficients and slopes between predicted and measured number of CCN during the selected time periods (CCN predictions as a function of CCN measured). The comparison during the recent biomass burning period showed two clear trends for the beginning and the end of the period.

\begin{tabular}{lllllll}
\hline Supersaturation & $\begin{array}{l}0.33 \% \\
\text { Correlation } \\
\text { coefficient, } \mathrm{r}^{2}\end{array}$ & Slope & $\begin{array}{l}0.66 \% \\
\text { Correlation } \\
\text { coefficient, } \mathrm{r}^{2}\end{array}$ & Slope & $\begin{array}{l}1.2 \% \\
\text { Correlation } \\
\text { coefficient, } \mathrm{r}^{2}\end{array}$ & Slope \\
\hline Entire period (23/7-28/7, with some interruptions) & 0.69 & 1.06 & 0.87 & 1.05 & 0.90 & 0.95 \\
Recent biomass burning (25/7 15:00-28/7 04:00) & 0.41 & 1.09 & 0.78 & 1.06 & 0.84 & 0.96 \\
Recent biomass burning I (25/7 15:00-26/7 12:00) & 0.77 & 1.45 & 0.93 & 1.30 & 0.95 & 1.14 \\
Recent biomass burning II (26/7 12:00-28/7 04:00) & 0.63 & 0.91 & 0.89 & 0.93 & 0.91 & 0.85 \\
Clean period & 0.92 & 0.99 & 0.94 & 0.98 & 0.97 & 0.85 \\
\hline
\end{tabular}

higher supersaturations. At this low supersaturation there are extremely few activated droplets. Due to the small detection volume in the $\mathrm{CCN}$ counter, the number concentrations vary in a stepwise fashion. Calculated correlations for this supersaturation provide no relevant information and are not included in Table 4. Also, the CCN counter is very sensitive to perturbations at this low supersaturation, and $0.12 \%$ supersaturation is out of the calibration range.

For the selected periods the predicted and measured CCN concentrations were averaged and plotted as a function of supersaturation (Fig. 5). The error bars represent the temporal variation given as one standard deviation. The different shapes of the CCN spectra for the various periods (clean period shows a flatter curve) were mainly due to the differences in number size distributions. The size distribution for the clean period was dominated by the accumulation mode while the distributions during the biomass burning periods were dominated by the Aitken mode. In Fig. 3, the key parameters determining the $\mathrm{CCN}$ spectra; the average number size distributions and activation diameter $d_{a c t}$ as a function of supersaturation are plotted for the three selected periods, as well as for the wet season in 1998. The average critical supersaturation of 1998 (in 1998 the aerosol was totally dominated by the less-hygroscopic mode, which means that the aerosol could be assumed to be internally mixed) coincided with that of the dominating less-hygroscopic mode for the clean period in 2001. The prediction of the CCN concentration for 1998 was made using the same model and compared to the results of the moderately clean period in 2001. The two background periods were seen to be in good agreement.

Table 4 presents a summary of the time-resolved CCN predictions, providing correlation coefficients and slopes (with zero intercept) between the predicted and measured CCN concentrations for the entire time period, as well as split into periods with similar air mass and other trends (the recent biomass burning period being split into two periods due to different trends in the $\mathrm{CCN}$ closure). In general, the estimated $\mathrm{CCN}$ concentrations agree very well with the actual measured values. Because the time resolution of the $\mathrm{CCN}$ counter was $6 \mathrm{~min}$, and $10 \mathrm{~min}$ for the model prediction, a moving average of $12 \mathrm{~min}$ was used for the CCN counter in the comparison.

\subsection{Model sensitivity study}

\subsubsection{External/internal mixture}

The first parameter investigated in the sensitivity study was the effect of treating the aerosol as internally or externally mixed. This comparison was motivated by the fact that in many atmospheric aerosol studies, H-TDMA data is not available, and $n_{i}$ therefore has to be evaluated from measurement techniques that provide no information about the aerosol mixing status. Size-resolved chemical data from analysis of cascade impactor samples is typically used for this purpose.

For the external mixture, the aerosol was divided into the two hygroscopic groups found with the H-TDMA. The CCN prediction was made separately for each hygroscopic group and summed. When treating the aerosol as internally mixed, the soluble volume fractions for each hygroscopic group at each dry size were averaged. The resulting difference between the two ways of treating the aerosol was investigated for two model salts; $\mathrm{NH}_{4} \mathrm{HSO}_{4}$ and $\mathrm{KCl}$. When applied to one time period (for the sensitivity study the recent biomass burning period is used), the predicted CCN concentrations were quite similar whether treating the aerosol as internally or externally mixed, with the external mixture resulting in slightly ( $\sim 5 \%)$ lower CCN concentrations (Fig. 6).

The resulting difference is due to the non-linear relationship between the critical supersaturation $s_{c}$ and $n_{i}$ $\left(s_{c}^{2} \propto 1 / n_{i}\right)$. The greater the difference in soluble volume fraction between the hygroscopic groups, the larger is the difference between CCN concentrations calculated as internally or externally mixed aerosol particles. During CLAIRE2001 , the difference in hygroscopic growth, and thereby $\varepsilon$, between the two hygroscopic groups was small. In addition, the particles were most often dominated by the lesshygroscopic group, which makes the approximation of an 
internal mixture quite accurate. This is not the case in several other types of air masses, such as a fresh urban (hydrophobic) aerosol superimposed on an aged (more-hygroscopic) background aerosol (Swietlicki et al., 1999; Cocker et al., 2001).

5.2.2 Model compound, non-ideality at activation and surface tension

Figure 6 also shows the sensitivity of the $\mathrm{CCN}$ predictions to the assumption of model compound. Using $\mathrm{KCl}$ instead of $\mathrm{NH}_{4} \mathrm{HSO}_{4}$ for an external or internal mixture resulted in $2-12 \%$ lower $\mathrm{CCN}$ concentrations for supersaturations $s_{c}=1.2-0.25 \%$, and about $30 \%$ lower for $s_{c}=0.12 \%$. Using $\left(\mathrm{NH}_{4}\right)_{2} \mathrm{SO}_{4}$ (made only assuming internally mixed aerosol) revealed a very similar result as for $\mathrm{NH}_{4} \mathrm{HSO}_{4}$. Also an inorganic-organic mixture MIXBIO was used as a model compound representing the soluble fraction of the particles. The predicted $\mathrm{CCN}$ concentrations were then found to be somewhat higher than for the pure inorganic salts. When performing these sensitivity calculations, water activity data for each compound was taken from Tang (1997), Tang and Munkelwitz (1994), and Svenningsson et al. (2004) ${ }^{1}$ describing the deviation from Raoult's law for concentrated solutions.

So far in our investigation, the non-ideality of the solution is taken into account for subsaturations (concentrated solutions), but are assumed to act like ideal solutions at activation. This is the approach for most of the CCN studies of this kind. One exception is Brechtel et al. (2000a), where the effect of the non-ideality of the salt solution at activation was investigated. One way of expressing the non-ideal behavior of a solution is to introduce the van't Hoff factor, $i$, and let it substitute for the number of soluble ions, $v$, in Eqs. (3) and (4). The van't Hoff factor for dilute solutions of both $\mathrm{KCl}$ and $\left(\mathrm{NH}_{4}\right)_{2} \mathrm{SO}_{4}$ have been published in Low (1969). For dilute solutions of $\mathrm{KCl} i$ is approximately $2(\sim 1.9)$, while for $\left(\mathrm{NH}_{4}\right)_{2} \mathrm{SO}_{4}(v=3) i$ is more dependent on solute concentration. For example, a particle with a dry diameter of $100 \mathrm{~nm}$ and a soluble volume fraction of 0.2 , has an $i$ of 2.34 at activation. Again making the $\mathrm{CCN}$ calculations with an internal mixture of $\left(\mathrm{NH}_{4}\right)_{2} \mathrm{SO}_{4}$ as a model salt, but now using a static van't Hoff factor of 2.34 at activation, the resulting $\mathrm{CCN}$ concentration was practically identical to that using an internal mixture of $\mathrm{KCl}$ (Fig. 6). In reality the van't Hoff factor varies slightly with concentration. We can see that the prediction in this case shows an even smaller dependence on which salt assumption the prediction is based on.

In order to simulate the sensitivity to surface-active compounds, the surface tension at activation was decreased by $15 \%$ from that of pure water. This was a limit estimated by Roberts et al. (2002) for the surface tension change in activating aerosol particles in the Amazon region. For comparison, according to the data given in Svenningsson et al. (2004) ${ }^{1}$, the surface tension of MIXBIO is $60 \mathrm{nN} \mathrm{m}^{-1}(-17 \%)$ at the point of activation for a $100 \mathrm{~nm}$ particle, and $54 \mathrm{nN} \mathrm{m}^{-1}$

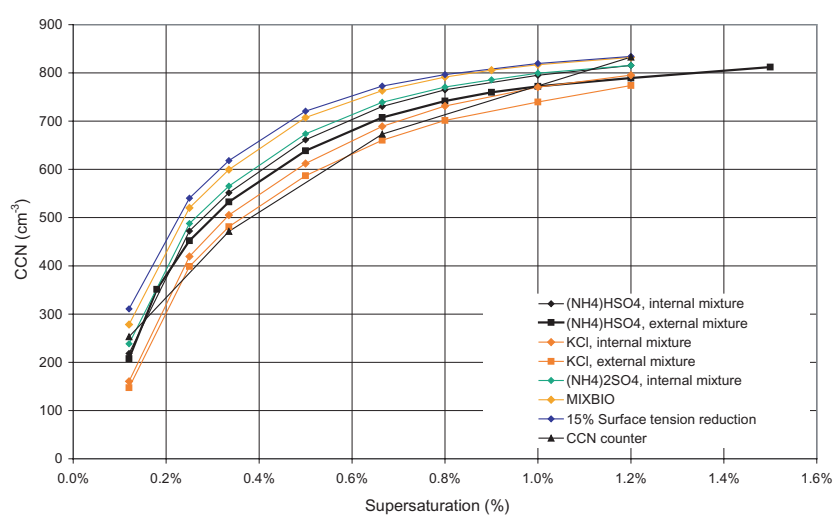

Fig. 6. The results of the model predictions for the period with influence of recent biomass burning using different assumptions of the aerosol mixing status and soluble compounds. The predictions were made both treating the two hygroscopic groups separately and as one using the average soluble volume fraction.

$(-25 \%)$ at the point of activation for $60 \mathrm{~nm}$ particles. This depression in surface tension for MIXBIO is mostly caused by the presence of fulvic acid. Again using $\mathrm{NH}_{4} \mathrm{HSO}_{4}$ as model compound, this gave an increase in $\mathrm{CCN}$ concentrations of about $3-14 \%$ for $s_{c}=1.2-0.25 \%$, and $42 \%$ for $s_{c}=0.12 \%$ (see Fig. 6). When doing these calculations, the soluble volume fractions were also estimated with the assumption of a $15 \%$ decrease in surface tension at $\mathrm{RH}=90 \%$. In reality, the surface tension might actually be substantially lower for concentrated solutions such as those found in aerosol particles at equilibrium at $\mathrm{RH}=90 \%$ (Facchini et al., 2000), but no measurements have been made for such high concentrations. On the other hand, the hygroscopic growth at subsaturation is not as sensitive to the Kelvin curvature correction term as the critical supersaturation at activation. The $\varepsilon$ estimated at sub-saturated conditions is therefore also quite insensitive to changes in surface tension.

A trend was seen in the $\mathrm{CCN}$ predictions based on the various model compounds, showing higher $\mathrm{CCN}$ concentrations as the hygroscopicity of the model compound decreased. However, the effect of applying different model compounds was not large. Even though the calculated value of the soluble volume fraction is sensitive to the selection of model compound, the number of soluble ions/molecules is not. As mentioned in Sect. 3, the difference in CCN predictions is only due to the non-ideality of the model compounds. It is worth noting that, if the soluble volume fractions are calculated assuming that Raoult's law is applicable for the entire range of solute concentrations, i.e. if the solutions are ideal, then all model compounds will predict exactly the same $\mathrm{CCN}$ concentration. The reason for this is that the estimated number of soluble molecules/ions (determining the growth at $90 \% \mathrm{RH}$ ) would be the same, irrespective of which model compound is used. The deviations in $\mathrm{CCN}$ predictions 


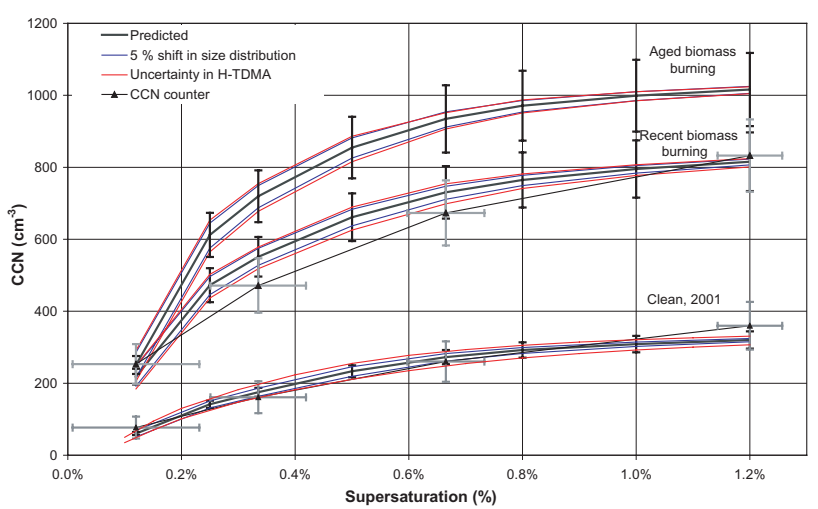

Fig. 7. A CCN model sensitivity study of number size distribution and measured hygroscopic growth factor. The basis of the sensitivity study is the calculation using ammonium hydrogen sulfate (internally mixed aerosol) as model salt (black curve). The blue curve shows the result of shifting size distribution 5\% up or down in size. The black error bars represent a shifting number concentration $\pm 10 \%$, and the red curve indicates the resulting error of the uncertainty in measured hygroscopic growth at $90 \% \mathrm{RH}( \pm 0.05$ in diameter growth factor). For the measured $\mathrm{CCN}$ concentrations, the grey error bars indicate the uncertainty in supersaturation $( \pm 1$ s.d.) as well as in number concentration ( \pm 1 s.d.).

seen in Fig. 6 is therefore a measure of the non-ideality of the model compounds at $\mathrm{RH}=90 \%$, with $\mathrm{KCl}$ behaving almost ideally.

\subsubsection{Particle sizing}

The particle volumes were determined from the DMPS measurements, while the soluble volume fractions were derived from H-TDMA data. Accurate particle sizing is therefore crucial when predicting CCN concentrations using this model. While any inaccuracy in particle concentrations in the DMPS (vertical axis in Fig. 3) is almost directly reflected in the number of predicted $\mathrm{CCN}$, the effect of inaccuracies in the sizing of the particles (horizontal axis in Fig. 3) is less obvious. Errors in DMPS particle concentrations are most likely caused by malfunctioning particle counters or an erroneous aerosol flow entering the DMA, while particle-sizing errors may have several causes. During field operation with well-calibrated DMPS instruments, the most likely source of particle sizing error is deviations from the nominal calibration values in the sheath air volume flow rate through the DMA.

The sensitivity of the $\mathrm{CCN}$ predictions to particle sizing errors was examined by shifting the particle diameters of the entire size distribution by $\pm 5 \%$. Separately, the number concentrations $\left(\mathrm{dN} / \mathrm{d} \log \mathrm{D}_{p}\right)$ were varied by $\pm 10 \%$. The effects of both these errors on the predicted CCN concentration are shown in Fig. 7. The calculations were made for each of the three selected time periods using an internally mixed aerosol with $\mathrm{NH}_{4} \mathrm{HSO}_{4}$ as model salt. A sizing error larger than $\pm 5 \%$ is not very likely in calibrated DMPS instruments. It is therefore comforting to see that possible errors induced via this sizing error are not very large.

When applying the DMA technique to measure particle volume equivalent diameters (used in $\mathrm{CCN}$ predictions), a shape factor has to be applied. Most often a spherical shape is assumed (unity shape factor), introducing a possible error in both the size distribution as well as in the H-TDMA-data. A non-spherical shape of the particles would then result in an overestimation of the measured dry diameters of the particles. The size distribution would be shifted towards larger diameters, resulting in an overestimation of $\mathrm{CCN}$ concentration, while the measured hygroscopic growth factor would be underestimated and lead to underestimation of the $\mathrm{CCN}$ concentration. The effects are of different signs and the total resulting effect would therefore be small. To give an example, a shape factor of 1.09 for $100 \mathrm{~nm}$ particles would result in a 5\% overestimation of size (compare with Fig. 7), while a shape factor of 1.07 would result in an underestimation of the growth factor of 0.05 (assuming a growth factor of 1.3 for a $100 \mathrm{~nm}$ particle). The shape factor for a cube is 1.08 . The result of these shape factors can be seen in Fig. 7 .

\subsubsection{Hygroscopic growth factor}

The uncertainty in the diameter growth factor measured with the H-TDMA also induces errors in the $\mathrm{CCN}$ predictions. The error in the measured diameter growth factor at $\mathrm{RH}=90 \%$ was estimated from repeated field calibrations with $\left(\mathrm{NH}_{4}\right)_{2} \mathrm{SO}_{4}$ salt particles to be a maximum of \pm 0.05 during field operation. The sensitivity of the predicted $\mathrm{CCN}$ concentrations to this possible error in the estimation of the number of soluble ions in each particle is also rather small (Fig. 7), and only slightly larger than the $\pm 5 \%$ in particle sizing. For the sensitivity test an internally mixed aerosol using $\mathrm{NH}_{4} \mathrm{HSO}_{4}$ as a model salt for the recent biomass burning period was used.

The calculation of the number of solute molecules or ions available at the point of activation hinges on the estimate of the soluble volume fraction derived from H-TDMA data at $\mathrm{RH}=90 \%$. Poorly soluble compounds might not be entirely in solution at this $\mathrm{RH}$, even though an aqueous phase is provided - in all but a few extreme cases - by the ubiquitous inorganic salts (Hämeri et al., 2002). Even though some inorganic salts present in the atmospheric aerosol have low solubility, the problem is more pertinent for the organic fraction. Compounds that are insoluble in water up to the point of droplet activation cause no problem, since they are incorporated in the insoluble component. $\mathrm{CCN}$ concentrations might however be underpredicted when a significant volume fraction of the aerosol particles consist of compounds that are not in solution at $\mathrm{RH}=90 \%$, but dissolve as the solution becomes more dilute up to the supersaturation at the point of activation. The sensitivity test for H-TDMA diameter 
growth factor measurement errors was also used to simulate the effect of compounds that are not completely dissolved at $\mathrm{RH}=90 \%$. Assume the case when, if all soluble material is in solution, the diameter growth would be 1.3 at $90 \% \mathrm{RH}$. If however $20 \%$ of the soluble particle volume is not yet in solution at this RH, but would go into solution before the point of activation, the growth factor is underestimated by 0.05 . The resulting increase in predicted $\mathrm{CCN}$ concentrations resulting from this increase in growth factor of 0.05 is the same as that shown in Fig. 7. Succinic acid is an example of a moderately soluble dicarboxylic acid of atmospheric relevance. Particles of the pure compound deliquesce only at an $\mathrm{RH} \approx 99 \%$ (Peng et al., 2001). Nevertheless, succinic acid goes partly into solution already at much lower RH when mixed with inorganic salts that provide the aqueous phase, as seen in the MIXBIO mixture (Svenningsson et al., 2004 ${ }^{1}$ ).

To further test how salt assumptions as well as solubility might affect the $\mathrm{CCN}$ predictions, MIXBIO was assumed to simulate the water-soluble fraction of a biomass-burning aerosol. The hygroscopic growth factors were first calculated for MIXBIO based on the water activity data given in Svenningsson et al. (2004) ${ }^{1}$. Then, these growth factors were treated as any other H-TDMA field data, that is the exact chemical composition of the aerosol particles was considered unknown. The critical supersaturation for a $100 \mathrm{~nm}$ particle was estimated from simulated H-TDMA measurements between $\mathrm{RH}=90-95 \%$, using $\left(\mathrm{NH}_{4} \mathrm{HSO}_{4},\left(\mathrm{NH}_{4}\right)_{2} \mathrm{SO}_{4}\right.$ and $\mathrm{KCl}$ respectively to represent the soluble molecules/ions. A slight decrease is seen in the supersaturation needed for activation when going from $\mathrm{RH}=90 \%$ to $95 \%$. The critical supersaturation decreased from 0.200 to $0.194 \%$ using $\mathrm{NH}_{4} \mathrm{HSO}_{4}$ as model compound, from 0.215 to $0.209 \%$ for $\left(\mathrm{NH}_{4}\right)_{2} \mathrm{SO}_{4}$, and from 0.243 to $0.234 \%$ for $\mathrm{KCl}$. Using $\mathrm{NaCl}$ instead as a model salt, an increase in critical supersaturation was observed. This shows that while the salt assumption and limited solubility of the organic compound present in MIXBIO had an effect in this RH range, it was not a large one and the slight change in supersaturation is certainly within the precision of most existing $\mathrm{CCN}$ counters.

For CCN prediction purposes alone, it would be advantageous to obtain the hygroscopic properties at an $\mathrm{RH}$ as close to $100 \%$ as possible. In the laboratory, it is quite possible to reach stable operating conditions for the H-TDMA even as high as $\mathrm{RH}=98.5 \%$ (Svenningsson et al., 2004 ${ }^{1}$ ). During field experiments, however, it is often difficult to obtain good quality data at a RH much higher than $90 \%$, at least with the H-TDMA instrument used during CLAIRE-2001. The most crucial factor is temperature control in the second humidified DMA. Improvements to the existing H-TDMA instruments might allow stable field measurements at $\mathrm{RH} \geq 95 \%$ in the future.

\section{Parameterization of CCN spectra}

Here, a single, simple formula is presented that enables direct calculation of $N_{C C N}\left(s_{C}\right)$ even when the chemical characterization of the aerosol is poor. The only input data required are a description of the average modal number size distribution, and an estimate of the size-averaged soluble volume fraction in each of the modes. Finally, a parameterization of the CCN concentrations for the various air masses, predicted using the detailed time resolved model described in Sect. 3, is given. This parameterization is based on the simple formulas presented below and fitted to the predicted $\mathrm{CCN}$ spectra.

The integral of a standardized normal distribution $N(0,1)$, with zero mean and unit variance, can be described with a cumulative distribution, $\phi(\mathrm{x})$, and approximated by (Råde and Westergren, 1995):

$\phi(x) \approx\left(1+e^{x\left(1.59145+0.01095 x+0.06651 x^{2}\right)}\right)^{-1}$.

The number of CCN, $N_{C C N}$, is derived by integration of the number size distribution from particle diameters $d=\infty$ down to $d=d_{a c t}$, the smallest dry diameter of a particle that activates. Assuming that the particle number size distribution is adequately described by a lognormal distribution, with total particle number concentration $N_{\text {tot }}$ in the mode, count median diameter (geometric mean diameter) $C M D$, and geometric standard deviation $\sigma_{g}$, this integral can be written as

$N_{C C N}=(1-\phi(x)) \cdot N_{t o t}$,

where $x$ is given by

$x=\frac{\log \left(d_{a c t}\right)-\log (C M D)}{\log \left(\sigma_{g}\right)}$.

Assuming that the particle soluble volume fraction $\varepsilon$ is independent of particle size within the particle mode, then $d_{a c t}$ can be expressed as (compare Eq. (4), and Eq. 15.34, Page 789, Seinfeld and Pandis, 1998)

$d_{a c t}=\left(\frac{4 A^{3} M_{s} \rho_{w}}{27 v M_{w} \rho_{s} \varepsilon s_{c}^{2}}\right)^{1 / 3}=\left(\frac{K}{\varepsilon \cdot s_{c}^{2}}\right)^{(1 / 3)}$.

For ammonium hydrogen sulfate at $26^{\circ} \mathrm{C}, K=1.61 \cdot 10^{-27} \mathrm{~m}^{3}$. This means that the number of particles activating to form cloud droplets as a function of the water vapor supersaturation, $N_{C C N}\left(s_{C}\right)$, can be predicted using Eq. (11), with $d_{a c t}$ taken from Eq. (13). It is important to point out that the same chemical composition used when estimating the particle soluble volume fraction $\varepsilon$, should be used when calculating $K$ (here ammonium hydrogen sulfate).

When the observed ambient particle number size distribution is bi- or multimodal, the total $\mathrm{CCN}$ concentration, $N_{C C N, t o t}\left(s_{C}\right)$, is simply the sum of the cumulative distributions for each of the $i=1, \mathrm{n}$ modes, each with different modal parameters $\left(C M D_{i}, \sigma_{g, i}, N_{\text {tot }, i}, \varepsilon_{i}\right)$ :

$N_{C C N, t o t}\left(s_{C}\right)=\sum_{i=1}^{n} N_{C C N, i}\left(s_{C}\right)$. 
Table 5. Parameters from fitting the average size distribution spectra of the selected time periods, fitted for sizes down to $29 \mathrm{~nm}$. Also presented is the root mean square deviation (RMSD) between the $\mathrm{CCN}$ spectra resulting from inserting the parameters into Eq. (13) and the $\mathrm{CCN}$ prediction described in the article.

\begin{tabular}{ccccc}
\hline & Clean 1998 & Clean 2001 & Recent biomass burning (2001) & Aged biomass burning (2001) \\
\hline CMD $(\mathrm{nm})$ & 67 & 73 & 66 & 67 \\
$\sigma_{g}$ & 1.4 & 1.4 & 1.31 & 1.27 \\
$\varepsilon$ & 0.14 & 0.155 & 0.19 & 0.19 \\
$\mathrm{~N}\left(\mathrm{~cm}^{-3}\right)$ & 234 & 194 & 266 & 274 \\
$\mathrm{CMD}(\mathrm{nm})$ & 149 & 154 & 144 & 138 \\
$\sigma_{g}$ & 1.4 & 1.4 & 1.44 & 1.42 \\
$\varepsilon$ & 0.2 & 0.23 & 0.26 & 0.25 \\
$\mathrm{~N}\left(\mathrm{~cm}^{-3}\right)$ & 164 & 151 & 554 & 747 \\
$\mathrm{RMSD}$ & 4.4 & 11.6 & 22.3 & 16.6 \\
\hline
\end{tabular}

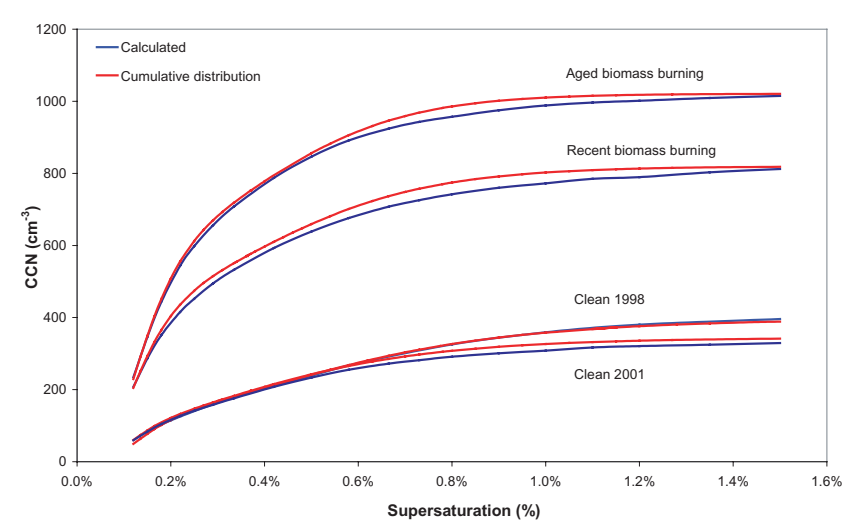

Fig. 8. A comparison using the detailed time resolved model (aerosol external mixture, ammonium hydrogen sulfate) and a model using only a fitting of the average size distribution and an average $\varepsilon$ estimated from the H-TDMA measurements.

The modal parameters used in equation 14 are presented in Table 5, and are derived from bimodal fits of the size distributions ( $d>29 \mathrm{~nm}$ only) when averaged over each of the defined time periods (shown in Fig. 3). They therefore differ slightly from the modal parameters given in Table 2, which are averages of the parameters of the log-normal fits of each measured (10-min) size distribution. The nucleation mode was excluded from the bimodal description in Table 5, as it is not important for determining CCN concentrations. The modal soluble volume fractions given in Table 5 are concentration-weighted time averages of the H-TDMA estimates of $\varepsilon$ for the dry sizes in the Aitken $(35,50$ and $75 \mathrm{~nm})$ and the accumulation modes respectively $(110,165$ and $265 \mathrm{~nm}$ ), again averaged over each of the defined time periods.

Figure 8 shows a comparison between $N_{C C N, t o t}\left(s_{c}\right)$ calculated using the non-time resolved bimodal description
(Eq. 14) and the more detailed model described in Sect. 3 (external mixture, $\mathrm{NH}_{4} \mathrm{HSO}_{4}$ ). In the detailed model (Sect. 3) the CCN spectra were calculated with a time resolution of 10 min using a size dependent $\varepsilon$, while for the simpler model the average size distribution and $\varepsilon$ was taken, as well as a size averaged value of $\varepsilon$ for each mode of the size distribution. It should be noted that both the models assume static conditions of $s_{c}$, in the sense that they ignore any dynamic interaction between growing droplets and their mutual competition for the available water vapor.

The simplified bimodal model nevertheless predicts the CCN concentrations well, and has the advantage of being easy to implement. The parameters used in equations 10 to 13 are all derived from first principles, and have physical meaning. However, average number size distributions and $\varepsilon$ might be difficult to estimate and use in air masses with high temporal variability.

In order to describe the time-average of the detailed model in a succinct form (described in Sect. 3), the predicted $N_{C C N, t o t}\left(s_{c}\right)$ spectrum was fitted to the unimodal form of Eq. (11). The unimodal parameters $\left(C M D, \sigma_{g}, N_{t o t}, \varepsilon\right)$ were allowed to vary freely in order to minimize the residual sumof-squares between the time-average of the detailed model and the unimodal description. The modeled and fitted curves are shown in Fig. 9 and the fitted parameters are given in Table 6. This parameterization can be used to estimate $\mathrm{CCN}$ concentrations for air masses similar to those classified in this work. When no other data on particle size distribution and chemical composition are available apart from the number concentration (30-1000 nm), the latter should be used to replace $N_{t o t}$, whilst keeping the other parameters $\left(C M D, \sigma_{g}\right.$, $\varepsilon$ ) as given in Table 6 . Alternatively, it might also be possible to derive $N_{\text {tot }}$ from modeled concentration fields of, for example, PM1 (aerosol particle mass for particles smaller than $1 \mu \mathrm{m}$ in diameter), assuming the same size distribution as for the air masses given here. 
Table 6. The resulting parameters from fitting one cumulative distribution, $\phi(\mathrm{x})$, to the predicted $\mathrm{CCN}$ spectra.

\begin{tabular}{ccccc}
\hline & Clean 1998 & Clean 2001 & Recent biomass burning & Aged biomass burning \\
\hline $\mathrm{CMD}(\mathrm{nm})$ & 85 & 95 & 102 & 117 \\
$\sigma_{g}$ & 2.3 & 2.0 & 2.0 & 1.8 \\
$\varepsilon$ & 0.11 & 0.17 & 0.29 & 0.22 \\
$\mathrm{~N}\left(\mathrm{~cm}^{-3}\right)$ & 488 & 352 & 843 & 1024 \\
$\mathrm{RMSD}\left(\mathrm{cm}^{-3}\right)$ & 7.0 & 2.2 & 6.1 & 9.3 \\
\hline
\end{tabular}

In conclusion, in this section a simpler time-average model is presented that is able to predict the CCN spectra. The model only requires as input a modal description of the dry particle number size distribution, and an estimate of the average water-soluble volume fraction $(\varepsilon)$ of the particles in each of the modes. When an H-TDMA instrument is not available for estimating $\varepsilon$, then size-resolved chemical information on soluble species has to be used, in combination with the total, often gravimetric, size-resolved particle mass, or alternatively published values of $\varepsilon$ typical of certain air masses and geographical regions.

A parameterization of the $\mathrm{CCN}$ spectrum $N_{C C N}\left(s_{c}\right)$, predicted using time resolved model is also given (Table 6). The resulting parameterization could be used for example in global climate models (Nenes and Seinfeld, 2003), in adiabatic cloud parcel models (Khain et al., 2001) or simply when comparing data from other measurements. Also, for direct estimates of $\mathrm{CCN}$ concentrations in the Amazon region (or other similar regions) during influence of the air mass types described here, the simplified unimodal parameterizations might be used, inserting the actual or assumed $N_{\text {tot }}$.

\section{Discussion and Conclusions}

Submicrometer particle physical properties (i.e. the number size distribution and hygroscopic properties) were measured in the Amazon basin during the wet-to-dry transition period. From these measurements, $\mathrm{CCN}$ concentrations were predicted and compared to those measured directly. Three time periods were selected for analysis, representative of clean background conditions, recent and aged biomass burning, impacting an area with only few other particle sources. The number size distribution in the diameter interval 30$850 \mathrm{~nm}$ exhibited average number concentrations of 360 , 860 and $1070 \mathrm{~cm}^{-3}$ for the different time periods, respectively. Taking the smallest and shortest-lived particles (3$30 \mathrm{~nm}$ ) also into account, average concentrations were instead 640,1230 and $1350 \mathrm{~cm}^{-3}$, respectively. The hygroscopic diameter growth factor was measured with an $\mathrm{H}$ TDMA. The hygroscopic growth often showed a bimodal structure, with one hygroscopic group clearly dominating the spectrum. The dominating group had a relatively stable growth over time, with an average diameter growth factor

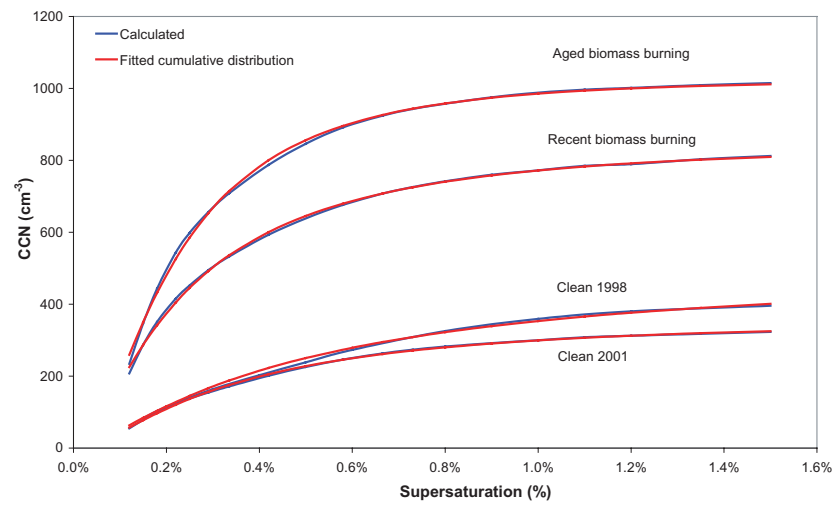

Fig. 9. A parameterization of the predicted CCN concentrations calculated using the time resolved model, in this case based on an externally mixed aerosol, with ammonium hydrogen sulfate as a model salt.

around 1.29 for $100 \mathrm{~nm}$ particles. The nearly hydrophobic group had an average of 1.06. Both groups showed a slight increase in hygroscopic growth as a function of dry size.

Particle number size distribution and the size-resolved hygroscopic properties are the two most important aerosol physical parameters determining $N_{C C N}$. In essence, the combination of these two properties yields the number of ions (or molecules dissolved in water) available for water uptake as a function of dry particle size. Here we used the measured physical properties to predict CCN concentrations and compare to those measured by a thermal-gradient $\mathrm{CCN}$-counter. Predicted and measured CCN concentrations showed good agreement. The non-ideal behavior of the solute is partly considered, applying the non-ideal behavior of a model salt.

The advantages of using the hygroscopic growth at subsaturation to estimate the critical supersaturation in CCN models are: (i) it provides high time resolution (less than $1 \mathrm{~h}$ ); (ii) it reveals the mixing status of the particles; (iii) all molecules in solution at $90 \% \mathrm{RH}$ are taken into account, even the organic fraction. Also, the effect of the particles having a nonspherical shape is diminished by the fact that both the DMPS and H-TDMA use DMA techniques to measure particle diameter. 
Some previous CCN closure studies based on a similar approach (predicting critical supersaturation from H-TDMA data) have also been able to predict $\mathrm{CCN}$ concentrations and spectra that agree satisfactorily with measurements (Brechtel et al., 2000b). Many other studies however over-predict CCN concentrations (Dusek et al., 2003; Covert, 1988; Zhou et al., 2001a; Chuang et al., 2000; Bigg, 1986). This discrepancy can, of course, be due to aerosol physical/chemical effects not taken into account in the prediction, but also due to multiple experimental biases. As already mentioned in Sect. 2.2.3, an important matter in our experimental study proved to be the calibration of the supersaturation in the $\mathrm{CCN}$ counter.

A sensitivity study was included to see how different parameters would affect the $N_{C C N}\left(s_{c}\right)$. When discussing these parameters two things have to be considered: (i) the sensitivity of the $\mathrm{CCN}$ counter response to the parameter in question, and (ii) the result of including or modifying the parameter in the CCN prediction model.

Considering the effects of organic compounds on a $\mathrm{CCN}$ closure, lowering the surface tension cannot explain the observed over-prediction of CCN concentrations seen in other studies. This would instead lead to even higher predicted $\mathrm{CCN}$ concentration, compared to the concentration measured with the CCN spectrometer. The same effect would follow if slightly soluble organic compounds that were not in solution at $90 \%$ RH would go into solution before droplet activation, as well as if soluble gases were present affecting the activation in the CCN counter (Laaksonen et al., 1998). The effect of organic coatings inhibiting the hygroscopic growth is more difficult to predict since this also affects the hygroscopic growth in the H-TDMA. Laboratory experiments have shown that even very thick coatings of hydrophobic liquids on inorganic core particles fail to inhibit or even modify the CCN activation behavior (Raymond and Pandis, 2003; Cruz and Pandis, 1998).

A parameterization of the predicted $N_{C C N}\left(s_{c}\right)$ is given here to be used in dynamic cloud modeling (Khain et al., 2001). Also, a very simple formula is suggested for an approximate prediction of $\mathrm{CCN}$ when only an average number size distribution is known, and the chemical information is poor.

Much effort has been put recently into understanding the cloud nucleating properties of aerosol particles, especially the effect of organic compounds. Even though this simple model successfully predicts the cloud nucleating properties of the aerosol for the cases studies here, we want to point out the importance of continuing the research to fully understand how organic and inorganic compounds interact in water droplet solutions and influence cloud properties. It is also important to continue the development of robust dynamic cloud models, as well as to generate parameterizations for use in global climate models (Nenes and Seinfeld, 2003).
Acknowledgements. We wish to thank F. Meixner, MPIC (Max Planck Institute for Chemistry), Mainz, Germany, for letting us use his meteorology data. We also want to acknowledge all the helpful people assisting us during the CLAIRE 2001 field operations in Balbina, especially B. Graham and P. Guyon, MPIC, Mainz, Germany. We thank G. Frank, MPIC and B. Svenningsson, Department of Chemistry, University of Copenhagen, Denmark for the calibration of the CCN spectrometer. We thank A. Setzer and R. Agop at INPE (Instituto Nacional de Pesquisas Espaciais) for the fire count map used in Fig. 1. We also would like to thank the Brazilian CNPq (Conselho Nacional de Desenvolvimento Cientifico e Tecnológico) and FAPESP (Fundação de Amparo à Pesquisa do Estado de São Paulo) for financial support.

The authors gratefully acknowledge the NOAA Air Resources Laboratory (ARL) for the provision of the HYSPLIT transport and dispersion model on the READY website (http://www.arl.noaa.gov/ready.html) used in this publication.

Edited by: B. Conant

\section{References}

Andreae, M. O.: Soot carbon and excess fine potassium: Longrange transport of combustion-derived aerosols, Science, 220, 1148-1151, 1983.

Andreae, M. O., Browell, E. V., Garstang, M., Gregory, G. L., Harriss, R. C., Hill, G. F., Jacob, D. J., Pereira, M. C., Sachse, G. W., Setzer, A. W., Dias, P. L. S., Talbot, R. W., Torres, A. L., and Wofsy, S. C.: Biomass-burning emissions and associated haze layers over Amazonia, J. Geophys. Res., 93, 1509-1527, 1988.

Andreae, M. O. and Merlet, P.: Emissions of trace gases and aerosols from biomass burning, Global Biogeochemical Cycles, 15, 4, 955-966, 2001.

Andreae, M. O., Rosenfeld, D., Artaxo, P., Costa, A. A., Frank, G. P., Longo, K. M., and Silva-Dias, M. A. F: Smoking rain clouds over the Amazon, Science, 303, 1337-1342, 27 February 2004.

Artaxo, P., Eduardo, T. F., Martins, J. V., Yamasoe, M. A., Hobbs, P. V., Maenhaut, W., Longo, K. M., and Castanho, A.: Largescale aerosol source apportionment in Amazonia, J. Geophys. Res., 103 (D24), 31 837-31 847, 1998.

Artaxo, P., Martins, J. V., Yamasoe, M. A., Procópio, A. S., Pauliquevis, T. M., Andreae, M. O., Guyon, P., Gatti, L. V., and Leal, A. M. C.: Physical and chemical properties of aerosols in the wet and dry season in Rondônia, Amazonia, J. Geophys. Res., 107, 8081, doi:10.1029/2001JD000666, 2002.

Anderson, T. L., Charlson, R. J., Schwartz, S. E., Knutti, R., Boucher, O., Rodhe, H., and Heintzenberg, J.: Climate forcing by aerosols - a hazy picture, Science, 300, 1103-1104, 2003.

Berg, O. H., Swietlicki, E., and Krejci, R.: Hygroscopic Growth of Aerosol Particles in the Marine Boundary Layer over the Pacific and Southern Oceans during the First Aerosol Characterization Experiment (ACE 1), J. Geophys. Res., 1013, 16535-16545, 1998.

Bigg, E. K.: Discrepancy between observation and prediction of concentrations of cloud condensation nuclei, Atmos. Res., 20, 81-86, 1986.

Brechtel, F. J. and Kreidenweis, S. M.: Predicting particles critical supersaturation from hygroscopic growth measurements in 
the humidified TDMA. Part I: Theory and sensitivity studies, J. Atmos. Science, 57, 1854-1871, 2000a.

Brechtel, F. J. and Kreidenweis, S. M.: Predicting particles critical supersaturation from hygroscopic growth measurements in the humidified TDMA. Part II: Laboratory and Ambient Studies, J. Atmos. Science, 57, 1872-1887, 2000b.

Cantrell, W., Shaw, G., Cass, G. R., Chowdhury, Z., Hughes, L. S., Prather, K. A, Guazzotti, S. A., and Coffee, K. R.: Closure between aerosol particles and cloud condensation nuclei at Kaashidhoo Climate Observatory, J. Geophys. Res., 106, 28 711-28 718, 2001.

Charlson, R. J., Seinfeld, J. H., Nenes, A., Kulmala, M., Laaksonen, A., and Fachini, M. C.: Reshaping the theory of cloud formation, Science, 292, 2025-2026, 2001.

Christensen, K. A., Stenholm, M., and Livbjerg, H.: The formation of submicron aerosol particles, $\mathrm{HCl}$ and $\mathrm{SO}_{2}$ in straw-fired boilers, J. Aerosol Sci., 29, 4, 421-444, 1998.

Chuang, P. Y., Collins, D. R., Pawalowska, H., Snider, J. R., Jonsson, H. H., Brenguir, J. L., Flagan, R. C., and Seinfeld, J. H.: $\mathrm{CCN}$ measurements during ACE-2 and their relationship to cloud microphysical properties, Tellus, 52B, 843-867, 2000.

Cocker, D. R., Withlock, N. E., Flagan, R. C., and Seinfeld, J. H.: Hygroscopic properties of Pasadena, California Aerosol, Aerosol Sci. Technol., 35, 637-647, 2001.

Covert, D. S., Gras, J. L., Wiedensohler, A., and Stratmann, F.: Comparison of directly measured $\mathrm{CCN}$ with $\mathrm{CCN}$ modeled from the number-size distribution in the marine boundary layer during ACE 1 at Cape Grim, Tasmania, J. Geophys. Res., 103, 16597$16608,1988$.

Crutzen, P. J. and Andreae M. O.: Biomass burning in the tropics: Impact on atmospheric chemistry and biochemical cycles, Science, 250, 1669-1678, 1990.

Cruz, C. N. and Pandis, S. N.: A study of the ability of pure secondary organic aerosol to act as cloud condensation nuclei, Atmos. Env., 31, 2205-2214, 1997.

Cruz, C. N. and Pandis, S. N.: The effect of organic coatings on the cloud condensation nuclei activation of inorganic atmospheric aerosol, J. Geophys. Res., 103, 13 111-13 123, 1998.

Decesari, S., Facchini, M. C., Fuzzi, S., and Tagliavini, E.: Characterization of water soluble organic compounds in atmospheric aerosol: a new approach, J. Geophys. Res., 105, 1481-1489, 2000.

Draxler, R. R. and Hess, G. D.: An Overview of the Hysplit_4 Modeling System for Trajectories, Dispersion, and Deposition, Aust. Met. Mag., 47, 295-308, (http://www.arl.noaa.gov/ss/models/ hysplit.html), 1998.

Dusek, U., Covert, D. S., Wiedensohler, A., Neusüss, C., Weise, D., and Cantrell, W.: Cloud condensation nuclei spectra derived from size distributions and hygroscopic properties of the aerosol in coastal south-west Portugal during ACE-2, Tellus, 55B, 3553, 2003.

Facchini, M. C., Decesari, S., Mirecea, M., Fuzzi, S., and Loglio, G.: Surface tension of wet aerosol and cloud/fog droplets in relation to their organic content and chemical composition, Atmos. Env., 34, 4853-4857, 2000.

Ganzeveld, L. N., Lelieveld, J., Dentener, F. J., Krol, M. C., and Roelofs, G.-J.: Atmosphere-biosphere trace gas exchanges simulated with a single-column model, J. Geophys. Res., 107 (D16), 4297, doi:10.1029/2001JD0004842002.
Gerab, F., Artaxo, P., Gillet, R., and Ayers, G.: PIXE, PIGE and ions chromatography of aerosol particles from north east Amazon Basin, Nucl. Industr. And Meth. B, 136-138, 955-960, 1998.

Gysel, M., Weingartner, E., and Baltensperger, M.: Hygroscopicity of Aerosol Particles at Low Temperatures. II. Theoretical and Experimental Hygroscopic Properties of Laboratory Generated Aerosols, Environ. Sci. Technol., 36, 63-68, 2002.

Hansson, H.-C., Rood, M. J., Koloutsou-Vakatis, S., Hämeri, K., Orsini, D., and Wiedensohler, A.: $\mathrm{NaCl}$ Aerosol Particle hygroscopicity dependence on mixing with organic compounds, J. Atmos. Chem., 31, 321-346, 1998.

Haywood, J., Francis, P., Dubovik, O., Glew, M., and Holben, B.: Comparison of aerosol size distributions, radiative properties, and optical depths determined by aircraft observations and Sun photometers during SAFARI 2000, J. Geophys. Res., 108 (D13), 8471, doi:10.1029/2002JD002250, 2003.

Hedberg, E., Kristensson, A., Ohlsson,M., Johansson, C., Johansson, P.-A., Swietlicki, E., Veseley, V., Widenqvist, U., and Westerholm, R.: Chemical and physical characterization of emissions from birch wood combustion in a wood stove, Atmos. Env., 36, 4823-4837, 2002.

Hoppel, W. A., Frick, G. M., and Fitzgerald, J. W.: A cloud chamber study of the effect that non precipitating water clouds have on aerosol size distribution, Aerosol Science and Technology, 20, 1-30, 1994.

Hämeri, K., Väkevä, M., Aalto, P. P., Kulmala, M., Swietlicki, E., Zhou, J., Seidl, W., Becker, E., and O'Dowd, C. D.: Hygroscopic and $\mathrm{CCN}$ properties of aerosol particles in boreal forests, Tellus, 53B, 359-379, 2001.

Hämeri, K., Charlson, R., and Hansson, H.-C.: Hygroscopic properties of mixed ammonium sulfate and carboxylic acids particles, AIChE Journal, 48, 6., 1309-1316, 2002.

Intergovernmental Panel on Climate Change (IPCC): Climate change, Third Assessment Report, Scientific Basis, 2001.

Kaufman, Y. J., Hobbs, P. V., Kirchhoff, V. W. J. H., Artaxo, P., Reer, L. A., Holben, B. N., King, M. D., Ward, D. E., Prins, E. M., Longo, K. M., Mattos, L. F., Nobre, C. A., Spinhirne, J. D., Ji, Q., Thompson, A. M., Gleason, J. F., Christopher, S. A., and Tsay, S.-C.: Smoke, Clouds, and Radiation-Brazil (SCAR-B) experiment, J. Geophys. Res., 103 (D24), 31 783-31808, 1998.

Köhler, H.: The Nucleus in and the Growth of Hygroscopic Droplets, Trans. Faraday. Soc. 32, 1152-1161, 1936.

Khain, A. P., Rosenfeld, D., and Pokrovsky, A.: Simulating convective clouds with sustained supercoold liquid water down to $-37.5^{\circ} \mathrm{C}$ using a spectral microphysics model, J. Geophys. Res., 28, 20, 3887-3890, October 15, 2001.

Kulmala, M., Pirjola, L., and Mäkelä, J. M.: Stable sulphate clusters as a source of new atmospheric particles, Lett. Nature, 404, 6669, 2000.

Laaksonen, A., Korhonen, P., Kulmala, M., and Charlsson, R. J.: Modification of the Köhler equation to include soluble trace gases and slightly soluble substances, J. Atmos. Science, 853 $862,1998$.

Low, R. D. H: A theoretical study of nineteen condensation nuclei, Journal de reserches atmosphériques, 4, 65-78, 1969.

Martinsson, B. G., Frank, G., Cederfelt, S.-L., Swietlicki, E., Berg, O. H., Zhou, J., Bower, K. N., Bradbury, C., Birmili, W., Stratmann, F., Wenelisch, M., Wiedernsohler, A., and Yuskiewicz, B. A.: Droplet Nucleation and growth of orographic clouds related 
to aerosol population, Atmos. Res., 50, 289-315, 1999.

Massling, A., Wiedensohler, A., Busch, B., Neusiuss, C., Quinn, P., Bates, T., and Covert, D.: Hygroscopic properties of different aerosol types over the Atlantic and Indian oceans, Atmos. Chem. Phys., 3, 1377-1397, 2003,

\section{SRef-ID: 1680-7324/acp/2003-3-1377.}

Nenes, A., Chuang, P. Y., Flagan, R. C., and Seinfeld, J. H.: A theoretical analysis of cloud condensation nucleus $(\mathrm{CCN})$ instruments, J. Geophys. Res., 106 (D4), 3449-3474, 2001 a.

Nenes, A., Ghan, S., Abdul-Razzak, H., Chuang, P. Y., and Seinfeld, J. H.: Kinetic limitations on cloud droplet formation and impact on cloud albedo, Tellus, 53B, 133-149, 2001b.

Nenes, A. and Seinfeld, J. H.: Parameterization of cloud droplet formation in global climate Models, J. Geophys. Res., 108 (D14), 4415, doi:10.1029/2002JD002911, 2003.

Nober, F. J., Graf, H.-F., and Rosenfeld, D.: Sensitivity of the global circulation to the suppression of precipitation by anthropogenic aerosols, Global and Planetary Change, 767, 1-24, 2003.

Novakov, T. and Penner, J. E: Large contribution of organic aerosols to could-condensation nuclei concentration, Nature, 365, 323$365,1993$.

Pagels, J., Strand, M., Rissler, J., Szpila, A., Gudmundsson, A., Bohgard, M., Lillieblad, L., Sanati, M., and Swietlicki, E.: Characteristics of Aerosol Particles Formed During Grate Combustion of Moist Forest Residue, J. Aerosol Sci., 34, 1043-1059, 2003.

Peng, C., Chan, M. N., and Chan, C. K.: The hygroscopic properties of dicarboxylic and multifunctional acids: measurements and UNIFAC predictions, Environmental Science \& Technology, 35 (22), 4495-4501, 2001.

Pitchford, M. L. and McMurry, P. H.: Relationship between measured water vapor growth and chemistry of atmospheric aerosol for Grand Canyon, Arizona, in winter 1990, Atm. Env., 28, 827839, 1994.

Raes, F., Van Dingenen, R., Vignati, E., Wilson, J., Putaud, J.-P., Seinfeld, J. H., and Adams, P.: Formation and cycling of aerosols in the global troposphere, Atm. Env., 34, 4215-4240, 2000.

Råde, L. and Westergren, B.: Mathematics handbook for Science and Engineering, 3rd Ed., 1995.

Raymond, T. M. and Pandis S. N.: Formation of cloud droplets by multicomponent organic Particles, J. Geophys Res., 108 (D15), 4469, doi:10.1029/2003JD003503, 2003.

Reid, J. S., Hobbs, P. V., Ferek, R. J., Blake, D. R., Martins, J. V., Dunlap, M. R., and Liousse, C.: Physical, chemical and optical properties of regional hazes dominated by smoke in Brazil, J. Geophys. Res., 103 (D24), 32 059-32 080, 1998.

Roberts, G. C., Andreae, M. O., Zhou, J., and Artaxo, P.: Cloud condensation nuclei in the Amazon Basin: "Marine" conditions over a continent?, Geophys. Res. Lett., 28, 2807-2810, 2001.

Roberts, G.: Cloud condensation nuclei in the Amazon Basin: Their role in a tropical rainforest, California Institute of Technology, Pasadena, CA, chapter 2, 2001.

Roberts, G. C., Artaxo, P., Zhou, J., Swietlicki, E., and Andreae, M. O.: Sensitivity of CCN spectra on chemical and physical properties of aerosol: A case study from the Amazon Basin, J. Geophys. Res., 107 (D20), 8070, doi:10.1029/2001JD000583, 2002.

Seinfeld, J. H. and Pandis, S. N.: Atmopheric chemistry and physics, from Air Pollution to Climate Change, 1998.

Simoneit, B. R. T, Schauer, J. J., Nolte, C. G., Oros, D. R., Elias, V. O., Fraser, M. P., Rogge, W. F., and Cass, G. R.: Levoglucosan, a tracer for cellulose in biomass burning and atmospheric particles, Atm. Env., 33, 173-182, 1999.

Snider, J. R., Guibert, S., Brenguier, J.-L., and Putaud, J.-P.: Aerosol activation in marine stratocumulus clouds: 2. Köhler and parcel theory closure studies, J. Geophys. Res., 108 (D15), 8629, doi:10.1029/2002JD002692, 2003.

Stolzenberg, M. R. and McMurry, P. H.: TDMAFIT user's manual. PTL Publications No.653, Particle Technology Laboratory, Department of Mechanical Eng., University of Minnesota, Minneapolis, MN, USA, 1988.

Svenningsson, B., Hansson, H.-C., and Wiedensohler, A.: Hygroscopic growth of aerosol particles in the Po Valley, Tellus, 44B, 556-569, 1992.

Svenningsson, B., Hansson, H.-C., Wiedensohler, A., Noone, K., Ogren, J., Hallberg, A., and Colvile, R.: Hygroscopic growth of aerosol particles in its influence of nucleation scavenging in cloud: Experimental Results from Kleiner Feldberg, J. Atmos. Chem., 19, 129-152, 1994.

Svenningsson, B.: Hygroscopic growth of atmospheric aerosol particles and its relation to nucleation scavenging in clouds, Doctoral dissertation at Lund University, Dep. of Nuclear physics, Lund, Sweden, ISBN 91-628-2764-2, 1997.

Swietlicki, E., Zhou, J., Berg, O. H., Martinsson, B. G., Frank, G., Cederfelt, S.-I., Dusek, U., Berner, A., Birmili, W., Wiedensohler, A., Yuskiewicz, B., and Bower, K. N.: A closure study of sub-micrometer aerosol particle hygroscopic behavior, Atmos. Res., 50, 205-240, 1999.

Swietlicki, E., Zhou, J., Covert, D. S., Hämeri, K., Busch, B., Väkevä, M., Dusek, U., Berg, O. H., Wiedensohler, A., Aalto, P., Mäkelä, J., Martinsson, B. G., Papaspiropoulos, G., Mentes, B., Frank, G., and Stratmann, F.: Hygroscopic properties of aerosol particles in the northeastern Atlantic during ACE-2, Tellus, 52B, 201-227, 2000.

Swietlicki, E., Vestin, A., Rissler, J., and Zhou, J.: Physical properties of the Amazonian dry season biomass burning aerosol, J. Aerosol Science, 34, S679-S680, 2003.

Tang, I. N. and Munkelwitz, H. R.: Water activities, densities, and refractive indices of aqueous sulfates and sodium nitrate droplets of atmospheric importance, J. Geophys. Res., 99, 18 801-18 808, 1994.

Tang, I. N.: Thermodynamic and optical properties of mixed-salt aerosols of atmospheric importance, J. Geophys. Res., 102 (D2), 1883-1893, 1997.

VanReken, T. M., Rissman, T. A., Roberts, G. C., Varutbangkul, V., Jonsson, H. H., Flagan, R. C., and Seinfeld J. H.: Toward aerosol/cloud condensation nuclei (CCN) closure during CRYSTAL-FACE, J. of Geophys. Res., 108 (D20), 4633, doi:10.1029/2003JD003582, 2003.

Vestin, A.: Size distribution and cloud nucleating properties of biomass burning aerosol in the Amazon basin, Master's Thesis at Lund University, Dept. of Nuclear physics, Lund, Sweden, LUTFD2/(TFKF-5046)/1-62/(2003), 2003.

Vestin, A., Swietlicki, E., Rissler, J., Zhou, J., and Frank, G.: CCN closure study for Amazonian dry season biomass burning aerosol, J. Aerosol Science, Proc of EAC 2003, S7-S8, 2004.

Williams, E., Rosenfeld, D., Madden, N., Gerlach, J., Gears, N., Atkinson, L., Dunnemann, N., Frostrom, G., Antonio, M., Biazon, B., Camargo, R., Franca, H., Gomes, A., Lima, M., Machado, R., Manhaes, S., Nachtigall, L., Piva, H., Quintil- 
iano, W., Machado, L., Artaxo, P., Roberts, G., Renno, N., Blakeslee, R., Bailey, J., Boccippio, D., Betts, A., Wolff, D., Roy, B., Halverson, J., Rickenbach, T., Fuentes, J., and Avelino, E.: Contrasting convective regimes over the Amazon: Implications for cloud electrification, J. Geophys. Res., 107 (D20), 8082, doi:10.1029/2001JD000380, 2002.

Winklmayr, W., Reischl, G. P., Linder, A. O., and Berner, A.: A new electric mobility spectrometer for the measurement of aerosol size distribution in size range from 1 to $1000 \mathrm{~nm}$, J. Aerosol Science, 22 (3), 289-196, 1991.

Yamasoe, M. Y., Artaxo, P., Miguel, H., and Allen, A. G.: Chemical composition of aerosol particles from direct emissions of vegetation fires in the Amazon Basin: water-soluble species and trace elements, Atm. Env., 34, 1641-1653, 2000.

Zhang, X. Q., McMurry, P. H., Hering, S. V., and Casuccio, G. S.: Mixing Characteristics and Water Content of Submicron Aerosols Measured in in Los Angeles and at the Grand Canyon, Atmos. Environ., 27A, 1593-1607, 1993.
Zhou, J., Swietlicki, E., Berg, O. H., Aalto, P., Hämeri, K., Nilsson, E. D., and Leck, C.: Hygroscopic properties of aerosol particles over the central Artic Ocean during summer, J. Geophys. Res., 106 (D23), 32 111-32 124, 2001a.

Zhou, J.: Hygroscopic properties of atmospheric aerosol particles in various environments, Doctoral dissertation, at Lund University, Dept. of Nuclear Physics, Lund, Sweden, ISBN 91-7874-120-3, 2001b.

Zhou, J., Swietlicki, E., Hansson, H. C., and Artaxo, P.: Submicrometer aerosol particle size distribution and hygroscopic growth measured in the Amazon rain forest during the wet season, J. Geophys. Res., 107 (D20), doi:10.1029/2000JD000203, 2002. 